ArgOn national laboratory

\title{
CONCEPTUAL DESIGN OF QUADRISO PARTICLES WITH EUROPIUM BURNABLE ABSORBER IN HTRS
}

Nuclear Engineering Division 


\begin{abstract}
About Argonne National Laboratory
Argonne is a U.S. Department of Energy laboratory managed by UChicago Argonne, LLC under contract DE-AC02-06CH11357. The Laboratory's main facility is outside Chicago, at 9700 South Cass Avenue, Argonne, Illinois 60439. For information about Argonne, see www.anl.gov.
\end{abstract}

\title{
Availability of This Report
}

This report is available, at no cost, at http://www.osti.gov/bridge. It is also available on paper to the U.S. Department of Energy and its contractors, for a processing fee, from:

U.S. Department of Energy

Office of Scientific and Technical Information

P.O. Box 62

Oak Ridge, TN 37831-0062

phone (865) 576-8401

fax (865) 576-5728

reports@adonis.osti.gov

\begin{abstract}
Disclaimer
This report was prepared as an account of work sponsored by an agency of the United States Government. Neither the United States Government nor any agency thereof, nor UChicago Argonne, LLC, nor any of their employees or officers, makes any warranty, express or implied, or assumes any legal liability or responsibility for the accuracy, completeness, or usefulness of any information, apparatus, product, or process disclosed, or represents that its use would not infringe privately owned rights. Reference herein to any specific commercial product, process, or service by trade name, trademark, manufacturer, or otherwise, does not necessarily constitute or imply its endorsement, recommendation, or favoring by the United States Government or any agency thereof. The views and opinions of document authors expressed herein do not necessarily state or reflect those of the United States Government or any agency thereof, Argonne National Laboratory, or UChicago Argonne, LLC.
\end{abstract}



EUROPIUM BURNABLE ABSORBER IN HTRS

by

Alberto Talamo

Nuclear Engineering Division, Argonne National Laboratory

March 2010 



\title{
CONCEPTUAL DESIGN OF QUADRISO PARTICLES WITH EUROPIUM BURNABLE ABSORBER IN HTRS
}

By

\author{
Alberto Talamo \\ Nuclear Engineering Division \\ Argonne National Laboratory \\ 9700 South Cass Avenue \\ Argonne, IL 60439
}

Argonne National Laboratory's work was supported by the U.S. Department of Energy under contract DE-AC02-06CH11357. 


\title{
CONCEPTUAL DESIGN OF QUADRISO PARTICLES WITH EUROPIUM BURNABLE ABSORBER IN HTRS
}

\author{
Table of Contents
}

$\underline{\text { Page }}$

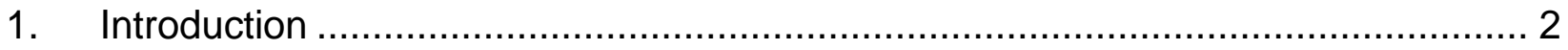

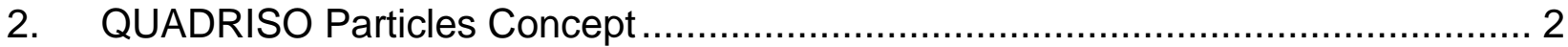

3. Prismatic HTR Performance with QUADRISO Particles ................................... 3

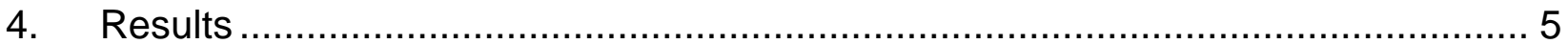

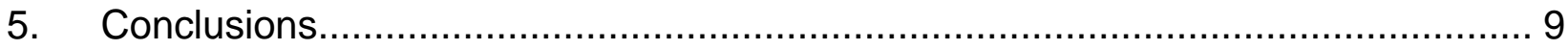




\title{
CONCEPTUAL DESIGN OF QUADRISO PARTICLES WITH EUROPIUM BURNABLE ABSORBER IN HTRS
}

\author{
List of Figures
}

Figure No.

$\underline{\text { Page }}$

Figure 1. Prismatic High Temperature Reactor. From the left to the right plot: reactor core, fuel block, fuel pin, and QUADRISO particle. The horizontal section of the reactor core is shown at the bottom of the left plot and it illustrates the 3 fuel rings (inner in dark-blue color, central in yellow color, and outer in blue color) with 36 fuel hexagonal blocks and graphite hexagonal blocks (in lightblue color). Legend: 1) fuel block, 2) graphite, 3) coolant channel, 4) fuel pin, 5) fuel particle, 6) fuel kernel, 7) burnable poison, 8) porous carbon, 9) inner pyrocarbon, 10) silicon carbide, 11) outer pyrocarbon. The position of the 6 corner pins with burnable poison (when used) is indicated by the BP label in the center-left plot (they are located at the 6 corners of the fuel block) ...... 16

Figure 2. Microscopic absorption cross section of ${ }^{10} \mathrm{~B},{ }^{113} \mathrm{Cd},{ }^{167} \mathrm{Er},{ }^{151} \mathrm{Eu},{ }^{155} \mathrm{Gd}$, ${ }^{157} \mathrm{Gd},{ }^{161} \mathrm{Dy},{ }^{164} \mathrm{Dy},{ }^{177} \mathrm{Hf}$, and ${ }^{149} \mathrm{Sm}$ in the thermal energy range, 0.01-1 eV and neutron spectrum of a prismatic HTR (lavender color and arbitrary units). The black circle highlights the increase of the europium and erbium absorption cross section in the region where the neutron spectrum (averaged in the core) decreases. The data of the neutron spectrum curve have been retrieved from Ref. 10

Figure 3. Multiplication factor as function of time for the europium burnable poison. The standard deviation is less than $60 \mathrm{pcm}$. The QUADRISO absorber layer thickness is equal to $10 \mu \mathrm{m}$

Figure 4. Microscopic and macroscopic cross sections of ${ }^{151} \mathrm{Eu}$ as function of time for the europium burnable poison. The QUADRISO absorber layer thickness is equal to $10 \mu \mathrm{m}$. For configurations 3 and 5 , the poison is distributed over a 40 and 26 times, respectively, higher volume relative to the QUADRISO configuration 18

Figure 5. Capture reaction rate of ${ }^{151} \mathrm{Eu}$ as function of time for the europium burnable poison. The QUADRISO absorber layer thickness is equal to $10 \mu \mathrm{m}$. For configurations 3 and 5, the poison is distributed over a 40 and 26 times, respectively, higher volume relative to the QUADRISO configuration 18

Figure 6. Microscopic and macroscopic fission cross sections of ${ }^{239} \mathrm{Pu}$ in the central ring as function of time for the europium burnable poison. The QUADRISO absorber layer thickness is equal to $10 \mu \mathrm{m}$ 19 
Figure 7. Fission reaction rate of ${ }^{239} \mathrm{Pu}$ in the central ring as function of time for the europium burnable poison. The QUADRISO absorber layer thickness is equal to $10 \mu \mathrm{m}$.

Figure 8. Microscopic and macroscopic cross sections of ${ }^{239} \mathrm{Pu}$ in the inner ring as function of time for the europium burnable poison. 20

Figure 9. Fission reaction rate of ${ }^{239} \mathrm{Pu}$ in the inner ring as function of time for the europium burnable poison 20

Figure 10. Microscopic and macroscopic cross sections of ${ }^{239} \mathrm{Pu}$ in the outer ring as function of time for the europium burnable poison

Figure 11. Fission reaction rate of ${ }^{239} \mathrm{Pu}$ in the outer ring as function of time for the europium burnable poison 21

Figure 12. Fission reaction rate of ${ }^{239} \mathrm{Pu}$ in the three rings as function of time for the europium burnable poison 22

Figure 13. Mass of ${ }^{151} \mathrm{Eu}$ and ${ }^{239} \mathrm{Pu}$ as function of time for the europium burnable poison of the central ring of the core. The QUADRISO absorber layer thickness is $10 \mu \mathrm{m}$ 22

Figure 14. Mass of ${ }^{239} \mathrm{Pu}$ and actinides as function of time for the europium burnable poison. The QUADRISO absorber layer thickness is equal to $10 \mu \mathrm{m}$ 23

Figure 15. Multiplication factor for configuration 1 (QUADRISO) as function of time for particles distributed in regular lattice, regular lattice with random perturbation, and random distribution 23

Figure 16. Multiplication factor as function of time for the erbium burnable poison. Standard deviation lower than $60 \mathrm{pcm}$. The QUADRISO absorber layer thickness is equal to $10 \mu \mathrm{m}$ 24

Figure 17. Mass of ${ }^{167} \mathrm{Er}$ and ${ }^{239} \mathrm{Pu}$ as function of time for the erbium burnable poison. The QUADRISO absorber layer thickness is equal to $10 \mu \mathrm{m}$

Figure 18. Multiplication factor as function of time for the erbium burnable poison. Standard deviation lower than $63 \mathrm{pcm}$. The QUADRISO absorber layer thickness is equal to $40 \mu \mathrm{m}$ 25

Figure 19. Mass of ${ }^{167} \mathrm{Er}$ and ${ }^{239} \mathrm{Pu}$ as function of time for the erbium burnable poison. The QUADRISO absorber layer thickness is equal to $40 \mu \mathrm{m}$ 25

Figure 20. Microscopic absorption cross section of ${ }^{151} \mathrm{Eu},{ }^{152} \mathrm{Eu},{ }^{153} \mathrm{Eu}$, and ${ }^{154} \mathrm{Eu}$, in the thermal energy range, $0.01-1 \mathrm{eV}$. 26 
Figure 21. Multiplication factor as function of time for different compositions of the europium burnable poison. The standard deviation is less than $63 \mathrm{pcm}$. The QUADRISO absorber layer thickness is equal to $10 \mu \mathrm{m}$ 26

Figure 22. Microscopic and macroscopic cross sections of ${ }^{151} \mathrm{Eu}$ as function of time for different compositions of the europium burnable poison. The QUADRISO absorber layer thickness is equal to $10 \mu \mathrm{m}$. For configurations 3 and 5 , the poison is distributed over a 40 and 26 times, respectively, higher volume relative to the QUADRISO configuration.

Figure 23. Capture reaction rate of ${ }^{151} \mathrm{Eu}$ as function of time for different compositions of the the europium burnable poison. The QUADRISO absorber layer thickness is equal to $10 \mu \mathrm{m}$. For configurations 3 and 5 , the poison is distributed over a 40 and 26 times, respectively, higher volume relative to the QUADRISO configuration 27

Figure 24. Microscopic and macroscopic fission cross sections of ${ }^{239} \mathrm{Pu}$ in the central ring as function of time for different compositions of the the europium burnable poison. The QUADRISO absorber layer thickness is equal to 10 $\mu \mathrm{m}$ 28

Figure 25. Fission reaction rate of ${ }^{239} \mathrm{Pu}$ in the central ring as function of time for different compositions of the europium burnable poison. The QUADRISO absorber layer thickness is equal to $10 \mu \mathrm{m}$ 28

Figure 26. Mass of ${ }^{151} \mathrm{Eu}$ and ${ }^{239} \mathrm{Pu}$ as function of time for the europium burnable poison of the central ring of the core. The QUADRISO absorber layer thickness is $10 \mu \mathrm{m}$...... 29

Figure 27. Mass of europium isotopes function of time for the natural europium burnable poison disposed in QUADRISO particles. The QUADRISO absorber layer thickness is $10 \mu \mathrm{m}$..... 29

Figure 28. $k_{\text {eff }}$ evolution for different compositions of the europium burnable poison. The horizontal ticks indicate the statistical error with $95 \%$ confidence 30 


\title{
CONCEPTUAL DESIGN OF QUADRISO PARTICLES WITH EUROPIUM BURNABLE ABSORBER IN HTRS
}

\author{
List of Tables
}

Table No.

Table I. Data of the prismatic HTR for the QUADRISO application.................. 13

Table II. Composition (atomic fraction) of the materials in the prismatic HTR for the QUADRISO application. Isotopes 162, 164, 168 and 170 of erbium do not affect neutron transport but only transmute according to their dosimetry cross sections

Table III. Power generated in the fuel particles [MW] and radial peak factor (defined as the maximum value between the rings divided the average) as function of the irradiation time. The values in the central ring include the Q-value of the neutron capture reaction in the burnable poison........................... 15 


\title{
CONCEPTUAL DESIGN OF QUADRISO PARTICLES WITH EUROPIUM BURNABLE ABSORBER IN HTRS
}

\begin{abstract}
In High Temperature Reactors, burnable absorbers are utilized to manage the excess reactivity at the early stage of the fuel cycle. In this study QUADRISO particles are proposed to manage the initial excess reactivity of High Temperature Reactors. The QUADRISO concept synergistically couples the decrease of the burnable poison with the decrease of the fissile materials at the fuel particle level. This mechanism is set up by introducing a burnable poison layer around the fuel kernel in ordinary TRISO particles or by mixing the burnable poison with any of the TRISO coated layers. At the beginning of life, the initial excess reactivity is small because some neutrons are absorbed in the burnable poison and they are prevented from entering the fuel kernel. At the end of life, when the absorber is almost depleted, more neutrons stream into the fuel kernel of QUADRISO particles causing fission reactions. The mechanism has been applied to a prismatic High Temperature Reactor with europium or erbium burnable absorbers, showing a significant reduction in the initial excess reactivity of the core.
\end{abstract}




\section{CONCEPTUAL DESIGN OF QUADRISO PARTICLES WITH EUROPIUM BURNABLE ABSORBER IN HTRS}

\section{Introduction}

The nuclear scientific community is investigating generation-IV of nuclear power plants with major design improvements compared to the current nuclear power plants. The primary goals of this investigation are: to have passive safety mechanisms for the reactor operation, to improve proliferation resistance, to optimize and close the fuel cycle, to improve energy conversion efficiency, and to reduce construction and operational costs. Within generation IV nuclear power plants, High Temperature Reactors (HTRs) are one of the promising candidates because of their unique capability for producing hydrogen for industrial applications. Two HTRs design concepts are considered based on the use of pebble bed and prismatic cores. Both are moderated by graphite and fuelled by TRISO particles. One of the major differences between a pebble bed and a prismatic HTR core is the refueling mode, which is continuous for the first core and every 1 to 2 years for the latter core. The continuous refueling of the pebble bed HTR allows a much smaller initial excess reactivity compared to the prismatic HTR and therefore it requires a smaller amount of burnable absorbers. In this study, the concept of QUADRISO particles is investigated for managing the initial excess reactivity. In the QUADRISO concept, the management of the excess of reactivity during burnup is caused not only by the absorber depletion at certain locations in the reactor core, but also by synergistically coupling the decrease of the poison and the decrease of the fissile materials at the fuel particle level. The concept is set up by placing an extra-layer of burnable poison surrounding the fuel kernel in ordinary TRISO particles. Alternatively, the poison can be mixed to any of the TRISO coating layers. It is beyond the scope of this study to define which configuration is the best from the manufacture and the operation point of views. The QUADRISO concept has been investigated for a prismatic HTR with europium or erbium burnable poison. These two absorbers have the advantage of enhancing the negative reactivity feedback in case of power excursion accident.

\section{QUADRISO Particles Concept}

In HTRs, TRISO particles contain a kernel of fuel oxide surrounded by concentric spherical layers of: ${ }^{1,2}$

- Porous carbon, which accommodate the fission gases and attenuates fission recoils.

- Pyrocarbon (inner layer), which sets the substrate for the SiC layer.

- SiC, which retains the fission gases and the fission products, and it provides the mechanical resistance for the fuel particle.

- Pyrocarbon (outer layer), which sets a bonding surface for compacting and it acts as fission products barrier in particles with defective SiC. 
The use of the burnable poison in nuclear reactors aims at decreasing the initial excess reactivity at the beginning of the fuel cycle by balancing the reactivity loss associated with fuel depletion with the reactivity gain associated with the absorber burnup. ${ }^{3}$ The traditional application of burnable poison to HTRs, started in the 70's, takes advantage of this concept. ${ }^{4}$ Within the traditional application, the flattening of the reactivity curve requires a certain ratio between the poison and the fuel cross sections, with the consequence that the ideal optimum burnable poison does not exist. The concept of QUADRISO particles aims at better managing the excess of reactivity relative to the traditional approach. In the QUADRISO design, the extra-layer of burnable poison surrounds the fuel kernel of ordinary TRISO particles, as illustrated in the right plot of Figure 1. In this design, the absorber depletion flattens the reactivity curve as function of time because the burnable poison depletion allows more neutrons to produce fission reactions in the fuel kernel. The QUADRISO particle concept was developed at Argonne National Laboratory while studying the booster configuration of the Yalina subcritical assembly. ${ }^{5}$ The QUADRISO concept has been applied in seperate studies for transmuting Neptunium and Plutonium from Light Water Reactors waste and for producing ${ }^{233} \mathrm{U}$ from thorium. ${ }^{6-10}$

\section{Prismatic HTR Performance with QUADRISO Particles}

As discussed in the Introduction section, the control of excess of reactivity during the fuel cycle is important for prismatic HTR cores because the refueling is a patch process. Increasing the operating time without refueling enhances the performance of the HTR. Among the burnable poison candidates, whose microscopic cross sections are illustrated in Figure 2, only europium and erbium produce a negative reactivity feedback in case of power excursion accident. In case of accident, the neutron spectrum shifts to the right and only a poison material with a positive slope at $\sim 0.2 \mathrm{eV}$ increases the neutron absorption producing a negative reactivity feedback. The shift of the neutron spectrum with increasing temperature is discussed and shown in Figures 9 and 19 of Reference 11.

A prismatic HTR with QUADRISO particles has been modeled without any geometrical homogenization using the MCNP/MCB Monte Carlo computer codes ${ }^{12-14}$ and continuous energy nuclear data libraries (JEF-2.2). The burnup capability of MCB was used for the analyses. The geometry and material data of the HTR are summarized in Tables I and II, respectively. The HTR core consists of a graphite cylinder with a radius of $4 \mathrm{~m}$ and a height of $10 \mathrm{~m}$ which includes $1 \mathrm{~m}$ axial reflectors at top and bottom, as illustrated in the left plot of Figure 1 . The core has three concentric fuel rings, each fuel ring consists of 36 hexagonal blocks with an interstitial gap of $0.2 \mathrm{~cm}$. Each hexagonal block contains 108 helium coolant channels and 216 fuel pins, central-left plot of Figure 1. Each fuel pin contains a random lattice of TRISO particles dispersed into a graphite matrix (central-right plot of Figure 1). In this core, the burnable absorbers have been utilized only in the central ring; therefore, the other two fuel rings do not load any poison material. The central ring uses QUADRISO particles in 210 fuel pins, which excludes the 6 corner pins. The other two rings always use ordinary TRISO particles in all 216 fuel

pins. Five different configurations, differing only for the poison distribution in the central ring, have been analyzed. The five different configurations are the following: 
1. No poison is used in the core and all the fuel consists of ordinary TRISO particles. The porous carbon layer thickness of the TRISO particles in the central ring is $160 \mu \mathrm{m}$ and the porous carbon density is decreased to have the same carbon mass as ordinary TRISO particles of $150 \mu \mathrm{m}$ thick porous carbon. The 6 corner pins of each hexagonal block in the central ring are filled with pure graphite.

2. $\mathrm{Eu}_{2} \mathrm{O}_{3}$ QUADRISO particles are used with $10 \mu \mathrm{m}$ absorber layer in the 210 fuel pins of the central ring. The porous carbon layer thickness of the QUADRISO particles in the central ring is $150 \mu \mathrm{m}$ with no density adjustment. The 6 corner pins of each hexagonal block in the central ring are filled by pure graphite.

3. The $\mathrm{Eu}_{2} \mathrm{O}_{3}$ layer of the QUADRISO particles in the 210 fuel pins of the central ring is replaced by porous carbon. The porous carbon layer thickness of the ordinary TRISO particles in the central ring is $160 \mu \mathrm{m}$ and the porous carbon density is decreased to have the same carbon mass as the ordinary TRISO particles. The mass of $\mathrm{Eu}_{2} \mathrm{O}_{3}$ of configuration 2 is reallocated and homogenized with graphite in the 6 corner pins of each hexagonal block of the central ring.

4. The $\mathrm{Eu}_{2} \mathrm{O}_{3}$ layer of the QUADRISO particles in the 210 fuel pins of the central ring is replaced by porous carbon. The porous carbon layer thickness of the TRISO particles in the central ring is $160 \mu \mathrm{m}$ and the porous carbon density is decreased to have the same carbon mass as the ordinary TRISO particles. The mass of $\mathrm{Eu}_{2} \mathrm{O}_{3}$ of configuration 2 is reallocated in the form of microspheres (the particles have $293.3 \mu \mathrm{m}$ radius and $0.1588 \mathrm{~cm}$ regular lattice side) in the 6 corner pins of each hexagonal block in the central ring and the corresponding graphite density of the 6 corner pins has been accordingly increased to maintain the same carbon mass as the previous configurations.

5. The $\mathrm{Eu}_{2} \mathrm{O}_{3}$ layer of the QUADRISO particles in the 210 fuel pins of the central ring is replaced by porous carbon. The porous carbon layer thickness of the TRISO particles in the central ring is $160 \mu \mathrm{m}$ with a decreased density to have the same carbon mass as the ordinary TRISO particles. The mass of $\mathrm{Eu}_{2} \mathrm{O}_{3}$ of configuration 2 is reallocated and homogenized with carbon in the outer pyrocarbon layer. The 6 corner pins of each hexagonal block in the central ring are filled by pure graphite.

The five configurations have the same mass of fuel, graphite and burnable poison (if it is used). In prismatic HTRs, the 6 corner pins usually allocate the burnable absorber. In the QUADRISO particles with the europium burnable poison, the width of the absorber layer is $10 \mu \mathrm{m}$. In the case of erbium, the width of the absorber layer is 10 or $40 \mu \mathrm{m}$ and these two configurations have been compared. The microscopic cross section of ${ }^{167} \mathrm{Er}$ is much smaller than ${ }^{151} \mathrm{Eu}$, as shown in Figure 2; the erbium smaller cross section has to be compensated by a thicker poison layer. In the five configurations, the thickness of the other layers of the QUADRISO particles exactly matches the corresponding values of TRISO particles.

The handling of the double heterogeneity of HTRs by Monte Carlo codes is important for calculating the correct multiplication factor as a function of time during burnup, as demonstrated by Plukiene and Ridikas. ${ }^{15}$ When the double heterogeneity is 
modeled in the Monte Carlo calculations of HTRs, the obtained results are accurate. Difilippo has shown an excellent agreement between MCNP (version 4) and experimental results in the range of 50 to $300 \mathrm{pcm}\left(1 \mathrm{pcm}=10^{-5}\right)$ for the multiplication factor of the pebble bed facility PROTEUS. ${ }^{16}$ Difilippo's model used structured, instead of random, particle distribution in the fuel pin and the TRISO particles were cut by the pebble fuel pin boundary. The impact of these two approximations have been studied in literature ${ }^{17-21}$ and the impact on the multiplication factor is about $200 \mathrm{pcm}$. In the QUADRISO particle concept, the absorber layer entirely covers the fuel kernel without any eventual cut by the pin boundary. Consequently, a special effort has been paid in the MCNP model to avoid cutting the particles at the fuel pin boundary. The structured fuel pin configuration has 45 particles (either TRISO or QUADRISO) in the xy plane allocated in a cubic lattice with $0.159 \mathrm{~cm}$ side. The structured lattice model has been compared with a random lattice of 450 particles along an axial height of $1.59 \mathrm{~cm}$ and no significant differences (about 150 $\mathrm{pcm}$ ) have been found in the multiplication factor. Since the MCB input for the random lattice is about 13000 lines and the input for a regular lattice is only 1700 lines and the two models provide very similar multiplication factors (Forrest Brown ${ }^{22}$ and Wei $\mathrm{ji}^{23}$ obtained the same result) all the simulations of this study used the regular lattice model.

\section{Results}

\section{A Europium Burnable Poison}

The results of the first four configurations described in section III are discussed in this section; the fifth configuration, mixing the burnable poison in the outer pyrocarbon, is analyzed in Section 4.C. Figure 3 shows the calculated multiplication factor as function of time for the five different configurations explained in the previous section. The QUADRISO particles configuration diminishes the multiplication factor by $5000 \mathrm{pcm}$ compared to the configuration with six homogeneous corner pins of burnable poison and by $17500 \mathrm{pcm}$ compared to the no-poison configuration. In the QUADRISO design, the reduction of the initial excess reactivity does not shorten the fuel cycle because the core is still critical after 500 days of operation; this is the same time as the other configurations. These results show that the QUADRISO particles flatten the reactivity profile during reactor operation.

The homogeneous europium configuration experiences an attenuated self-shielding effect compared to the europium in the microspheres configuration. This enhances the neutron absorption of the poison of the homogeneous configuration and results in more poison depletion. As a consequence, the multiplication factor for the microspheres configuration is $2500 \mathrm{pcm}$ higher than the one of the homogeneous configuration (Figure 3 configuration 3 and 4). A detailed comparison between homogeneous, microspheres and needlecylinders burnable poison configurations can be found in Ref. 24.

Figure 4 shows the one energy group microscopic (top plot) and macroscopic (bottom plot) cross sections of ${ }^{151} \mathrm{Eu}$. The microscopic cross section is calculated by MCB and the macroscopic cross section is obtained by multiplying the microscopic cross section by the atomic density of the poison. The increase of the microscopic cross section during operation is caused by the poison depletion, which reduces the self-shielding effect. The

value of the ${ }^{151} \mathrm{Eu}$ microscopic cross section of the QUADRISO configuration is higher 
than the other configurations because the ${ }^{151}$ Eu poison is homogeneously distributed in the core and that reduces the self-shielding. More precisely, in configurations 2 and 5 , the burnable poison is distributed within 210 fuel pins per fuel block of the central ring; in configurations 3 and 4 , the burnable poison is distributed within 6 corner pins per fuel block of the central ring. Consistently, the values of the ${ }^{151} \mathrm{Eu}$ microscopic cross sections for the microspheres and homogeneous configurations are quite close (about $200 \mathrm{~b}$ at beginning of irradiation). The number of burnable poison atoms in the core is the same for all configurations; however, for configurations 3 and 5 , the poison is distributed over a larger volume relative to the QUADRISO configuration. Due to the lower self-shielding effect in the QUADRISO configuration, a higher slope of the ${ }^{151} \mathrm{Eu}$ macroscopic cross section as a function of time is observed in the bottom plot of Figure 4. By contrast, the ${ }^{151} \mathrm{Eu}$ macroscopic cross section associated with the microspheres configuration (due to the highest self-shielding effect) exhibits the lowest slope of the macroscopic cross section as function of time, as shown in the bottom plot of Figure 4. The absorption reaction rate per unit volume follows the profile of the macroscopic cross section, as illustrated in Figures 4 and 5.

The ${ }^{239} \mathrm{Pu}$ microscopic and macroscopic fission cross sections in the central ring are plot in Figure 6. The ranking order of the plutonium microscopic cross section of the four configurations is reversed compared to the burnable absorber microscopic cross section curves as shown in the top plots of Figures 6 and 4 . In the QUADRISO configuration, the burnable absorber surrounds the fuel kernel, which attenuates the thermal neutron flux in the fuel and reduces the one-group ${ }^{239} \mathrm{Pu}$ microscopic cross section. In the homogeneous configuration, due to the smaller self-shielding effect compared to the microspheres configuration, the ${ }^{151} \mathrm{Eu}$ poison absorbs more thermal neutrons. This results in a harder neutron spectrum, which reduces the one-group ${ }^{239} \mathrm{Pu}$ microscopic cross section relative to the microsphere configuration. The diminishing of the ${ }^{239} \mathrm{Pu}$ macroscopic cross section as a function of time (bottom plot of Figure 6) is due to the fuel depletion. For the QUADRISO configuration, the ${ }^{239} \mathrm{Pu}$ macroscopic cross section remains almost constant during operation since the increase of the one-group microscopic cross section is balanced by the reduction of the ${ }^{239} \mathrm{Pu}$ atomic density.

In the central ring with the QUADRISO particles, the ${ }^{239} \mathrm{Pu}$ fission reaction rate increases during operation (Figure 7). This is a unique characteristic of the QUADRISO fuel concept. This increase of the plutonium fission rate is caused by the burnable poison depletion, which surrounds the fuel kernel. The depletion of the burnable poison allows more thermal neutrons to stream into the fuel kernel.

Figures 8 and 9 plot ${ }^{239} \mathrm{Pu}$ fission cross section and reaction rate in the inner ring. The inner ring does not load any poison since the fuel is TRISO particles. Consequently, the ${ }^{239} \mathrm{Pu}$ fission cross section of the inner ring is similar for all the configurations. The QUADRISO configuration shows a sharper decrease of the fission reaction rate due to the constant power normalization. More precisely, the sharper decrease of the fission reaction rate in the inner ring compensates the increase of the fission reaction rate in the central ring. Figures 10 and 11 plot ${ }^{239} \mathrm{Pu}$ fission cross section and reaction rate in the outer ring and show no significant difference between the various configurations. Figure 
12 shows that the ${ }^{239} \mathrm{Pu}$ fission reaction rate diminishes uniformly in the core in all burnable poison configurations.

Figure 13 depicts the mass of ${ }^{151} \mathrm{Eu}$ in the top plot and ${ }^{239} \mathrm{Pu}$ in the bottom plot as function of time in the central ring. The QUADRISO configuration depletes most of the ${ }^{151} \mathrm{Eu}$ (about 99\%) at the expense of a smaller increase in the ${ }^{239} \mathrm{Pu}$ leftover. The result for the homogeneous configuration is in-between the results for QUADRISO and microspheres configurations. Figure 14 plots the ${ }^{239} \mathrm{Pu}$ and actinides mass in the core (as sum over the three rings) as function of time for the different configurations, which shows similar masses because of the constant power normalization.

Table III summarizes the power generated in the fuel particles of the core and the radial peak factor as function of time. About $4 \%$ of the thermal power $\left(\sim 17 \mathrm{MW}_{\mathrm{th}}\right)$ is generated in graphite. The total thermal power of the core is $600 \mathrm{MW}_{\text {th. }}$ In all configurations, the inner ring contributes to the largest fraction of the total power. At the begin of irradiation, the QUADRISO configuration exhibits a higher peaking factor of 1.4 relative to the traditional designs of 1.3. This can be adjusted by allocating some of the QUADRISO particles in the inner ring; however, this configuration requires a more sophisticated MCNP modeling. At the end of irradiation, all configurations have a peak factor close to one.

\section{B Effect of the Random Particle Distribution}

In the regular lattice, 45 particles are distributed in the $x y$ plane and the cubic unit cell of the lattice has a side of $0.159 \mathrm{~cm}$. The effect of the random distribution of the fuel particles in the fuel pin has been investigated by replacing the regular lattice with two different types of random distributions. In the first random distribution, it has been introduced a random perturbation in the position of the 45 particles with the only constrain that the particle is contained in the cubic unit cell. In the second random distribution, 450 particles have been randomly distributed in a pin height of $1.59 \mathrm{~cm}$, which represents only $60 \%$ of the mean free path of thermal neutrons in pure graphite. ${ }^{3}$ However, the mean free path of thermal neutrons in graphite filled with fuel particles is much smaller than the value in pure graphite due to the higher cross section of the fuel. This effect is also amplified by the use of plutonium fuel because of the strong resonances of ${ }^{239} \mathrm{Pu}$ and ${ }^{241} \mathrm{Pu}$ microscopic cross sections between 0.2 and $0.3 \mathrm{eV}$. Both in the regular lattice and in the random distribution MCNP modeling, the fuel particles are not cut by the fuel pin boundary. In the two random distribution models, both TRISO and QUADRISO particles are randomly distributed. The multiplication factor for the QUADRISO configuration modeled with a regular lattice is $1.14788 \pm 45$. When the position of the fuel particles is randomly perturbed (within the cubic unit cell), the multiplication factor changes to $1.14836 \pm 51$. When the fuel particles are randomly distributed, the multiplication factor changes to $1.14894 \pm 58$. The differences are within the statistical error with 95\% confidence; Figure 15 shows that this small differences are also preserved during burnup. These results are consistent with the ones found by Forrest Brown ${ }^{22}$ for a prismatic HTR full core calculation with regular lattice and random distribution when particles are not cut at the pin boundary. For a completely different fuel composition and configuration, Forrest Brown calculated a multiplication factor of 
$1.09740 \pm 20$ and $1.09680 \pm 20$ for the regular lattice and the random distribution, ${ }^{22}$ respectively. Also in the calculation of Forrest Brown, the difference is within the statistical error with the $95 \%$ confidence.

In line with present and Forrest Brown results, Wei Ji has also found a difference of $150 \mathrm{pcm}$ between the results for regular lattice and those for stochastic distribution of the fuel particles. ${ }^{23}$

\section{C Alternative Configurations for the QUADRISO Concept}

In the QUADRISO concept the poison can be mixed in any of the coating layers of ordinary TRISO particles or in the fuel kernel. ${ }^{25}$ It is beyond the scope of the present study to select the optimum configuration taken into consideration the manufacture, the best thermo-mechanical, and the chemical performance issues.

QUADRISO particles with a $10 \mu \mathrm{m}$ layer of ZrC deposited next to the fuel kernel have been fabricated for reducing the pressure on the Sic layer by absorbing oxygen. The irradiation of the oxygen getter QUADRISO particles revealed a good performance. ${ }^{26-28}$ The alternative configuration of mixing the poison in the outer pyrocarbon is configuration 5 in Figures 3 to 14. The volume of the outer pyrocarbon is about 26 times higher than the shell volume of $10 \mu \mathrm{m}$ surrounding the fuel kernel in the QUADRISO particle. The allocation of the burnable poison into a larger volume reduces the self-shielding effect. Consequently, the burnable poison microscopic cross section for this configuration is higher than the value for the QUADRISO configuration, as shown in the top plot of Figure 4. This results in a lower multiplication factor, as shown in Figure 3 , and a faster depletion of the burnable poison, as shown in Figures 5 and 13.

\section{D Erbium Burnable Poison}

The first four configurations for the europium burnable poison discussed in Section 4.A have been also considered for the erbium burnable poison. All previous remarks hold, however the burnable poison effects are rather mitigated. ${ }^{151} \mathrm{Eu}$ microscopic cross section is much higher, 3.3 times at $0.2 \mathrm{eV}$, the energy which marks the peak of the neutron spectrum, than the one of ${ }^{167} \mathrm{Er}$, as shown in Figure 2. Consequently, the differences between the three burnable poison configurations (2: QUADRISO, 3: homogeneous, and 4: microspheres) become much smaller and the obtained control of the initial excess of reactivity is quite small as shown in Figure 16. The transmuted mass of ${ }^{239} \mathrm{Pu}$ in the central ring is almost identical for all the three different configurations as shown in the bottom plot of Figure 17,. However, the depletion of ${ }^{167} \mathrm{Er}$ is similar to the previous results for ${ }^{151} \mathrm{Eu}$ as shown in the top plot of Figure 17 and 13.

The effect of erbium on the control of excess of reactivity is much stronger if the thickness of the ${ }^{167} \mathrm{Er}$ layer in the QUADRISO configuration is $40 \mu \mathrm{m}$, as shown in Figure 18. The $40 \mu \mathrm{m}$ of erbium are equivalent to $10 \mu \mathrm{m}$ of europium from the results of Figures 18 and 3. The depletion of the ${ }^{239} \mathrm{Pu}$ and ${ }^{167} \mathrm{Er}$ are shown in Figure 19 for the different configurations as a function of time. 


\section{E Natural Europium Burnable Poison}

The results shown in Sections 4.A, 4.B, and 4.C have been calculated using ${ }^{151} \mathrm{Eu}$ and ${ }^{152} \mathrm{Eu}$ in the europium composition, according to the atomic fractions reported in Table II. Natural europium contains only isotopes ${ }^{151} \mathrm{Eu}$ and ${ }^{153} \mathrm{Eu}$ with atomic fractions 47.8 and $52.2 \%$, respectively. Figure 20 illustrates the microscopic absorption cross section of ${ }^{151} \mathrm{Eu}$ and ${ }^{153} \mathrm{Eu}$ and their transmutation daughters ${ }^{152} \mathrm{Eu}$ (which has a decay half-life equal to 13.54 years) and ${ }^{154} \mathrm{Eu}$ (which has a decay half-life equal to 8.59 years). All europium isotopes have a very large absorption cross section at thermal energies. Figures 21-26 compare the results shown in Figures 3-7 and 13 with the results obtained with natural europium. The results obtained with the use of natural europium are similar to those obtained with the use of ${ }^{151} \mathrm{Eu}$ and ${ }^{152} \mathrm{Eu}$. The multiplication factor obtained by the use ${ }^{151} \mathrm{Eu}$ and ${ }^{152} \mathrm{Eu}$ is much smaller than the value obtained by natural europium due to the much higher cross section of ${ }^{152} \mathrm{Eu}$ relative to ${ }^{153} \mathrm{Eu}$ (Figure 20).

Figure 27 shows the mass of europium isotopes as function of time for the natural europium disposed in QUADRISO particles (in the central ring of the core). ${ }^{151} \mathrm{Eu}$ depletes whereas ${ }^{154} \mathrm{Eu}$ builds up due to ${ }^{153} \mathrm{Eu}$ capture reactions. ${ }^{152} \mathrm{Eu}$ first builds up and then it depletes by transmuting into ${ }^{153} \mathrm{Eu}$, whose mass little change with irradiation time.

Figure 28 shows the comparison between natural europium and europium with ${ }^{151} \mathrm{Eu}$ and ${ }^{152} \mathrm{Eu}$ for the results shown in Figure 7 of Reference 24 . Also in this case, the use of ${ }^{152} \mathrm{Eu}$ instead of ${ }^{153} \mathrm{Eu}$ considerably decreases the multiplication factor.

In Reference 29, the use of ${ }^{151} \mathrm{Eu}$ and ${ }^{152} \mathrm{Eu}$ sets a multiplication factor of 1.00469 $( \pm 63 \mathrm{pcm})$ and $0.99089( \pm 65 \mathrm{pcm})$ at the beginning of life and after 10 irradiation days, respectively. The use of natural europium changes these results into 1.01036 ( $\pm 58 \mathrm{pcm})$ and $0.99518( \pm 57 \mathrm{pcm})$.

\section{Conclusions}

The concept of QUADRISO particles has been investigated for the long term control of excess of reactivity. The concept takes advantage of increasing the neutron streaming into the fuel kernel as the burnable poison depletes. Alternative designs mix the burnable poison with any of the coating layers of the ordinary TRISO particles or with the fuel kernel. Further analyses and irradiation experiments can assess the optimum configuration considering the different engineering issues. The performances of the QUADRISO particles have been compared to the traditional design of burnable poison where the poison is distributed in the 6 corner pins of the fuel hexagonal block in prismatic High Temperature Reactors. The results have shown that the QUADRISO particles flatten the multiplication factor as function of the irradiation time and can control about $12500 \mathrm{pcm}$ in the initial multiplication factor when a width of $10 \mu \mathrm{m}$ or $40 \mu \mathrm{m}$ is used for europium or erbium oxides, respectively. In the QUADRISO configuration the poison depletes faster, which flattens the reactivity as function of time. The results for the poison homogeneously distributed in the 6 corner pins configuration are in-between the 
QUADRISO configuration and the poison heterogeneously (in microspheres) distributed in the 6 corner pins configuration. This is due to the different intensity of the selfshielding. Mixing the burnable poison in the outer pyrocarbon layer provides very similar results to the QUADRISO design. The use of natural europium instead of ${ }^{151} \mathrm{Eu}$ and ${ }^{152} \mathrm{Eu}$ europium increases the multiplication factor.

The effect of the randomness of the particles inside the fuel pin is negligible, as also found by Forrest Brown ${ }^{22}$ and Wei $\mathrm{Ji}^{23}$ in independent studies. QUADRISO particles with a $10 \mu \mathrm{m}$ of layer of ZrC deposited next to the fuel kernel have been already manufactured and they have shown good irradiation performances. ${ }^{26-28}$

\section{Acknowledgments}

Argonne National Laboratory's work was supported by the U.S. Department of Energy under contract DE-AC02-06CH11357. 


\section{References}

[1] K. Sawa et al. Safety Criteria and Quality Control of HTTR Fuel. Nuclear Engineering and Design 208, pp. 305-313, 2001.

[2] H. Nabielek et al. Performance of High-Temperature Reactor Fuel Particles at Extreme Temperature.. Nuclear Technology 84, pp. 62-81, 1989.

[3] J.J. Duderstadt and L.J. Hamilton. Nuclear Reactor Analysis. John Wiley \& Sons, ISBN 0-471-22363-8, 1976.

[4] J.D. Noden. Gadolinium Burnable Poison for High Temperature Reactors. Nuclear Engineering International 18/207, pp. 641-646, 1973.

[5] A. Talamo et al. Modeling of the Yalina Booster Facility by the Monte Carlo Code MONK. Proceedings of the ACCAPP conference, Pocatello, USA, 2007.

[6] A. Talamo. Conceptual Design of QUADRISO Particles for High Temperature Reactors. ANS, Summer Meeting, Anaheim, USA, 2008.

[7] A. Talamo. Simulation of an Accident Scenario for a One Pass Deep Burn Based on QUADRISO Particles. ANS, Winter Meeting, Reno, USA, 2008.

[8] A. Talamo. A Novel Concept of QUADRISO Particles Part I: Transmutation Neptunium and Plutonium. Annals of Nuclear Energy 35/10, 2008.

[9] A. Talamo. A Novel Concept of QUADRISO Particles Part II: Utilization for Excess Reactivity Control. Nuclear Engineering and Design, in press, 2010.

[10] A. Talamo. A Novel Concept of QUADRISO Particles Part III: Applications to the Plutonium-Thorium Fuel Cycle. Progress in Nuclear Energy 51/2, 2009.

[11] A. Talamo et al. Key Physical Parameters and Temperature Reactivity Coefficients of the Deep Burn Modular Helium Reactor Fuelled with LWRs Waste. Annals of Nuclear Energy 31, 2004.

[12] J.F. Briesmeister. A General Monte Carlo N-Particle Transport Code - Version 4c. LA-13709-M, LANL, 2002.

[13] J. Cetnar et al. MCB: a Continuous Energy Monte Carlo Burnup Simulation Code. EUR 18898 EN, OECD/NEA 523, 1999.

[14] J. Cetnar et al. Simulation of Nuclide Transmutation with Monte-Carlo Continuous Energy Burnup Code (MCB1C). Proceedings of the ADTTA Conference, Reno, USA, 2001.

[15] R. Plukiene and D. Ridikas. Modelling of HTRs with Monte Carlo: from a homogeneous to an exact heterogeneous core with microparticles. Annals of Nuclear Energy 30, pp. 1573-1585 (2003).

[16] F.C. Difilippo. Monte Carlo Calculations of Pebble Bed Benchmark Configurations of the Proteus Facility. Nuclear Science and Engineering 143, pp. 240-253, 2003.

[17] F.C. Difilippo. Reactivity Biases in the Simulation of the Random Dispersal of Fuel: the Case of the VHTR Fuel Compacts. American Nuclear Society Summer Meeting, Reno, NV, USA, 2006.

[18] F. Brown et al. Stochastic Geometry and HTGR Modeling with MCNP5. LA-UR-048668, 2005.

[19] F. Brown et al. Stochastic Geometry and HTGR Modeling with MCNP5. Proc. Monte Carlo 2005 Topical Meeting, Chattanooga, TN, USA, 2005.

[20] F. Brown and W.R. Martin. Stochastic Geometry Capability in MCNP5 for Analysis of Particle Fuel. Annals of Nuclear Energy 31, pp. 2039-2047, 2004. 
[21] U. Colak and V. Seker. Monte Carlo Calculations for a Pebble Bed Reactor with MCNP. Nuclear Science and Engineering 149, pp. 131-137, 2005.

[22] F. Brown. Theory and Practice of Criticality Calculations with MCNP5. Course given at the Argonne National Laboratory, LA-UR-08-0849, July 16-18, 2008.

[23] W. Ji. Neutronic Analysis of Stochastic Distribution of Fuel Particles in Very High Temperature Gas-Cooled Reactors. The University of Michigan, Ph.D. Dissertation, 2008.

[24] A. Talamo. Effects of the Burnable Poison Heterogeneity on the Long Term Control of Excess of Reactivity. Annals of Nuclear Energy, 33/9, pp. 794-803, 2006.

[25] A. Talamo et al. Alternative Configurations for the QUADRISO Fuel Design Concept. Journal of Nuclear Materials 383/3, p.264-266, 2009.

[26] R.E. Bullock and J.L. Kaae. Performances of Coated $\mathrm{UO}_{2}$ Particles Gettered with ZrC. Journal of Nuclear Materials 115, 1983.

[27] R.E. Bullock. Fission-Product Release During Post Irradiation Annealing of Several Types of Coated Fuel Particles. Journal of Nuclear Materials 125, 1984.

[28] D. Wongsawaeng. Performance Modeling of Deep Burn TRISO Fuel Using ZrC as a Load-Bearing Layer and Oxygen Getter. Journal of Nuclear Materials 396, 2010.

[29] A. Talamo and W. Gudowski. Incineration of Light Water Reactor Waste in HighTemperature Gas Reactors: Axial Fuel Management and Efficiency of Americium and Curium Transmutation. Nuclear Science and Engineering 156, 2007. 
Table I. Data of the prismatic HTR for the QUADRISO application

\begin{tabular}{|c|c|}
\hline Thermal Power [MW] & 600 \\
\hline Core - radius/height [m] & $4 / 10$ \\
\hline Hexagonal Blocks - number per ring/rings & $36 / 3$ \\
\hline Hexagonal Blocks - apothem/height/gap [cm] & $17.898 / 79.3 / 0.2$ \\
\hline Hexagonal Blocks - fuel pins inner ring/central ring/outer ring & 216/210/216 \\
\hline Hexagonal Blocks - coolant channels & 108 \\
\hline Hexagonal Blocks - burnable poison pins (only central ring) & 6 \\
\hline Hexagonal Blocks - fuel pins radius/hole/pitch [cm] & $0.6223 / 0.635 / 1.8796$ \\
\hline Hexagonal Blocks - coolant channel radius [cm] & 0.7937 \\
\hline TRISO Particles - kernel radius $[\mu \mathrm{m}]$ & 150 \\
\hline TRISO Particles - width porous carbon layer $[\mu \mathrm{m}]$ & 150 \\
\hline TRISO Particles - width inner pyrocarbon layer $[\mu \mathrm{m}]$ & 35 \\
\hline TRISO Particles - width SiC layer $[\mu \mathrm{m}]$ & 35 \\
\hline TRISO Particles - width outer pyrocarbon layer $[\mu \mathrm{m}]$ & 40 \\
\hline TRISO Particles - regular lattice side $[\mathrm{cm}]$ & 0.1588 \\
\hline
\end{tabular}


Table II. Composition (atomic fraction) of the materials in the prismatic HTR for the QUADRISO application. Isotopes 162, 164, 168 and 170 of erbium do not affect neutron transport but only transmute according to their dosimetry cross sections

\begin{tabular}{|c|c|}
\hline \multicolumn{2}{|c|}{$\begin{array}{l}\text { Neptunium and Plutonium Fuel } \\
\mathrm{NpPuO}_{1.7} \rho=10.2\left[\mathrm{~g} / \mathrm{cm}^{3}\right] \mathrm{T}=1500 \mathrm{~K}\end{array}$} \\
\hline${ }^{237} \mathrm{~Np}$ & 1.91 \\
\hline${ }^{238} \mathrm{Pu}$ & 0.56 \\
\hline${ }^{239} \mathrm{Pu}$ & 21.11 \\
\hline${ }^{240} \mathrm{Pu}$ & 8.5 \\
\hline${ }^{241} \mathrm{Pu}$ & 3.09 \\
\hline${ }^{242} \mathrm{Pu}$ & 1.87 \\
\hline${ }^{16} \mathrm{O}$ & 62.96 \\
\hline \multicolumn{2}{|c|}{$\begin{array}{c}\text { TRISO Porous Carbon Layer } \\
c_{\rho=1}\left[\mathrm{~g} / \mathrm{cm}^{3}\right] \mathrm{T}=1200 \mathrm{~K} \mathrm{~T} \mathrm{~T}_{\mathrm{S}(\alpha, \beta)}=1200 \mathrm{~K}\end{array}$} \\
\hline $\mathrm{C}$ & 100 \\
\hline \multicolumn{2}{|c|}{ 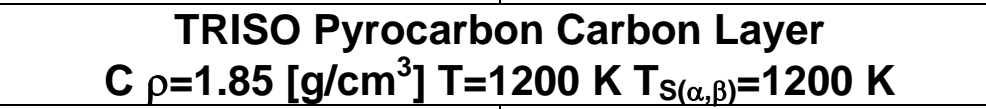 } \\
\hline C & 100 \\
\hline \multicolumn{2}{|c|}{$\begin{array}{l}\text { TRISO Silicon Carbide Layer } \\
\mathrm{SiC} \rho=3.2\left[\mathrm{~g} / \mathrm{cm}^{3}\right] \mathrm{T}=1200 \mathrm{~K}\end{array}$} \\
\hline $\mathrm{Si}$ & 50 \\
\hline $\mathrm{C}$ & 50 \\
\hline \multicolumn{2}{|c|}{$\begin{array}{c}\text { Graphite } \\
C_{\rho}=1.74\left[\mathrm{~g} / \mathrm{cm}^{3}\right] \mathrm{T}=1200 \mathrm{~K} \mathrm{~T}(\alpha, \beta)=1200 \mathrm{~K}\end{array}$} \\
\hline $\mathrm{C}$ & 100 \\
\hline \multicolumn{2}{|c|}{$\begin{array}{c}\text { Graphite (bottom axial reflector and pure graphite } \\
\text { hexagonal blocks) } \\
C_{\rho=1.74\left[\mathrm{~g}^{2} \mathrm{~cm}^{3}\right] \mathrm{T}=900 \mathrm{~K} \mathrm{~T}(\alpha, \beta)}=800 \mathrm{~K}\end{array}$} \\
\hline $\mathrm{C}$ & 100 \\
\hline \multicolumn{2}{|c|}{$\begin{array}{l}\text { Europium Burnable Poison } \\
\mathrm{Eu}_{2} \mathrm{O}_{3} \rho=7.28\left[\mathrm{~g} / \mathrm{cm}^{3}\right] \mathrm{T}=1200\end{array}$} \\
\hline${ }^{151} \mathrm{Eu}$ & 19.12 \\
\hline${ }^{152} \mathrm{Eu}$ & 20.88 \\
\hline${ }^{16} \mathrm{O}$ & 60 \\
\hline \multicolumn{2}{|c|}{$\begin{array}{c}\text { Erbium Burnable Poison } \\
\mathrm{Er}_{2} \mathrm{O}_{3} \rho=4.8633\left[\mathrm{~g} / \mathrm{cm}^{3}\right] \mathrm{T}=1200\end{array}$} \\
\hline${ }^{166} \mathrm{Er}$ & 23.78 \\
\hline${ }^{167} \mathrm{Er}$ & 16.22 \\
\hline${ }^{16} \mathrm{O}$ & 0.6 \\
\hline${ }^{162} E r$ & 0.096 \\
\hline${ }^{164} \mathrm{Er}$ & 1.14 \\
\hline${ }^{168} \mathrm{Er}$ & 18.95 \\
\hline${ }^{170} \mathrm{Er}$ & 10.56 \\
\hline
\end{tabular}


Table III. Power generated in the fuel particles [MW] and radial peak factor (defined as the maximum value between the rings divided the average) as function of the irradiation time. The values in the central ring include the Q-value of the neutron capture reaction in the burnable poison

\begin{tabular}{|c|c|c|c|c|c|c|}
\hline \multicolumn{2}{|c|}{ Irradiation Time } & $\begin{array}{c}0 \\
\text { Days }\end{array}$ & $\begin{array}{c}100 \\
\text { Days }\end{array}$ & $\begin{array}{l}200 \\
\text { Days }\end{array}$ & $\begin{array}{c}300 \\
\text { Days }\end{array}$ & $\begin{array}{l}400 \\
\text { Days }\end{array}$ \\
\hline \multirow{5}{*}{$\begin{array}{l}\text { Configuration } \\
\text { 2: QUADRISO }\end{array}$} & Inner Ring & 273 & 251 & 234 & 218 & 203 \\
\hline & Central Ring & 114 & 130 & 145 & 163 & 179 \\
\hline & Outer Ring & 195 & 198 & 199 & 197 & 195 \\
\hline & Total & 582 & 578 & 578 & 577 & 577 \\
\hline & $\begin{array}{l}\text { Peaking } \\
\text { Factor }\end{array}$ & 1.4 & 1.3 & 1.2 & 1.1 & 1.1 \\
\hline \multirow{5}{*}{$\begin{array}{c}\text { Configuration } \\
\text { 3: } \\
\text { Homogeneous } \\
6 \text { pins }\end{array}$} & Inner Ring & 245 & 236 & 228 & 220 & 207 \\
\hline & Central Ring & 144 & 149 & 156 & 165 & 177 \\
\hline & Outer Ring & 194 & 194 & 194 & 193 & 193 \\
\hline & Total & 583 & 579 & 578 & 577 & 577 \\
\hline & $\begin{array}{l}\text { Peaking } \\
\text { Factor }\end{array}$ & 1.3 & 1.2 & 1.2 & 1.1 & 1.1 \\
\hline \multirow{5}{*}{$\begin{array}{c}\text { Configuration } \\
4: \\
\text { Microspheres } \\
6 \text { pins }\end{array}$} & Inner Ring & 239 & 230 & 224 & 219 & 209 \\
\hline & Central Ring & 149 & 154 & 159 & 167 & 177 \\
\hline & Outer Ring & 195 & 195 & 195 & 192 & 191 \\
\hline & Total & 584 & 579 & 578 & 578 & 577 \\
\hline & $\begin{array}{c}\text { Peaking } \\
\text { Factor }\end{array}$ & 1.2 & 1.2 & 1.2 & 1.1 & 1.1 \\
\hline \multirow{5}{*}{$\begin{array}{c}\text { Configuration } \\
\text { 5: Outer } \\
\text { Pyrocarbon }\end{array}$} & Inner Ring & 283 & 253 & 233 & 216 & 202 \\
\hline & Central Ring & 107 & 127 & 146 & 164 & 180 \\
\hline & Outer Ring & 192 & 198 & 199 & 198 & 195 \\
\hline & Total & 582 & 578 & 578 & 577 & 577 \\
\hline & $\begin{array}{l}\text { Peaking } \\
\text { Factor }\end{array}$ & 1.5 & 1.3 & 1.2 & 1.1 & 1.0 \\
\hline
\end{tabular}



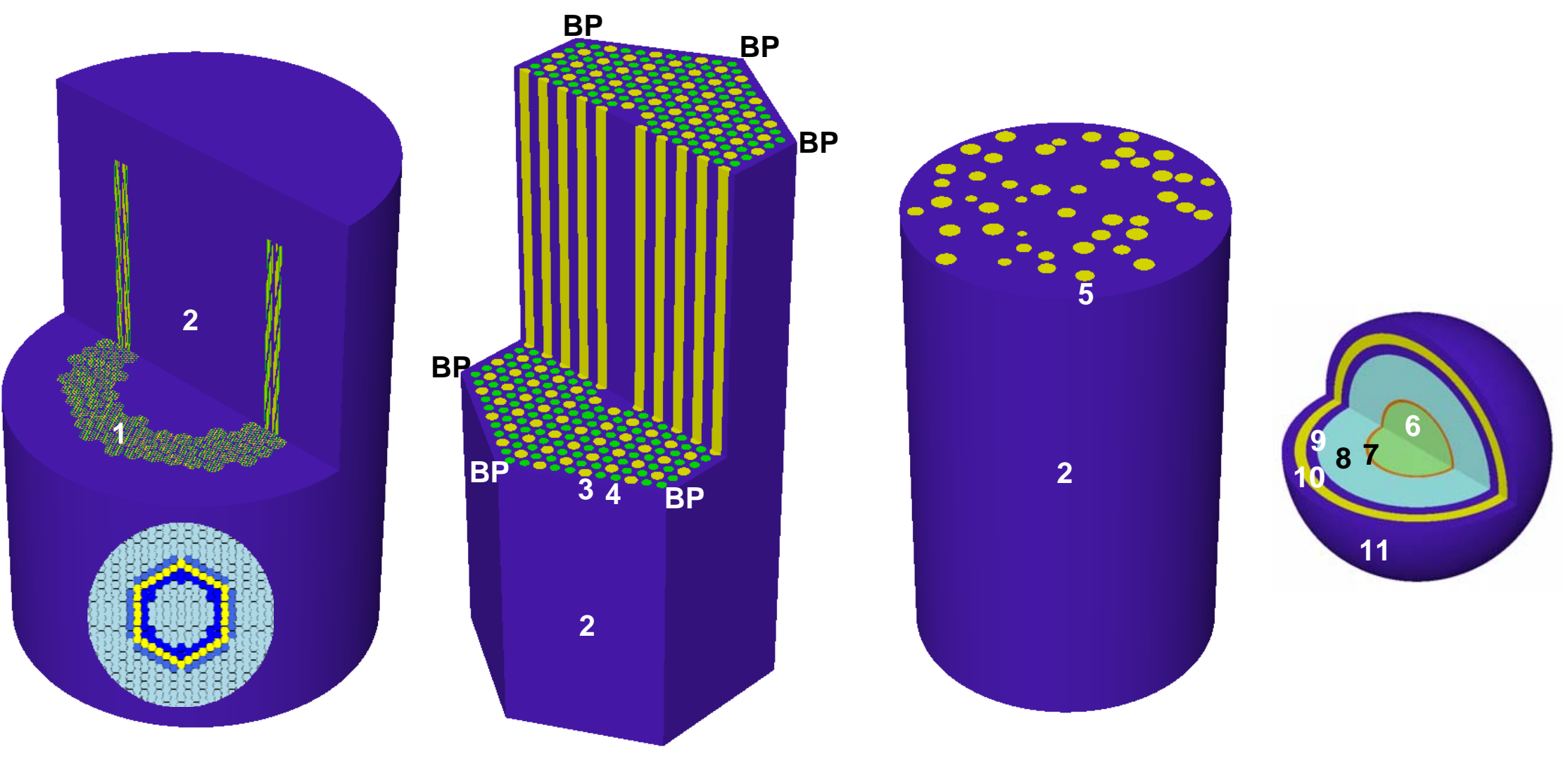

Figure 1. Prismatic High Temperature Reactor. From the left to the right plot: reactor core, fuel block, fuel pin, and QUADRISO particle. The horizontal section of the reactor core is shown at the bottom of the left plot and it illustrates the 3 fuel rings (inner in dark-blue color, central in yellow color, and outer in blue color) with 36 fuel hexagonal blocks and graphite hexagonal blocks (in light-blue color). Legend: 1) fuel block, 2) graphite, 3) coolant channel, 4) fuel pin, 5) fuel particle, 6) fuel kernel, 7) burnable poison, 8) porous carbon, 9) inner pyrocarbon, 10) silicon carbide, 11) outer pyrocarbon. The position of the 6 corner pins with burnable poison (when used) is indicated by the BP label in the centerleft plot (they are located at the 6 corners of the fuel block) 


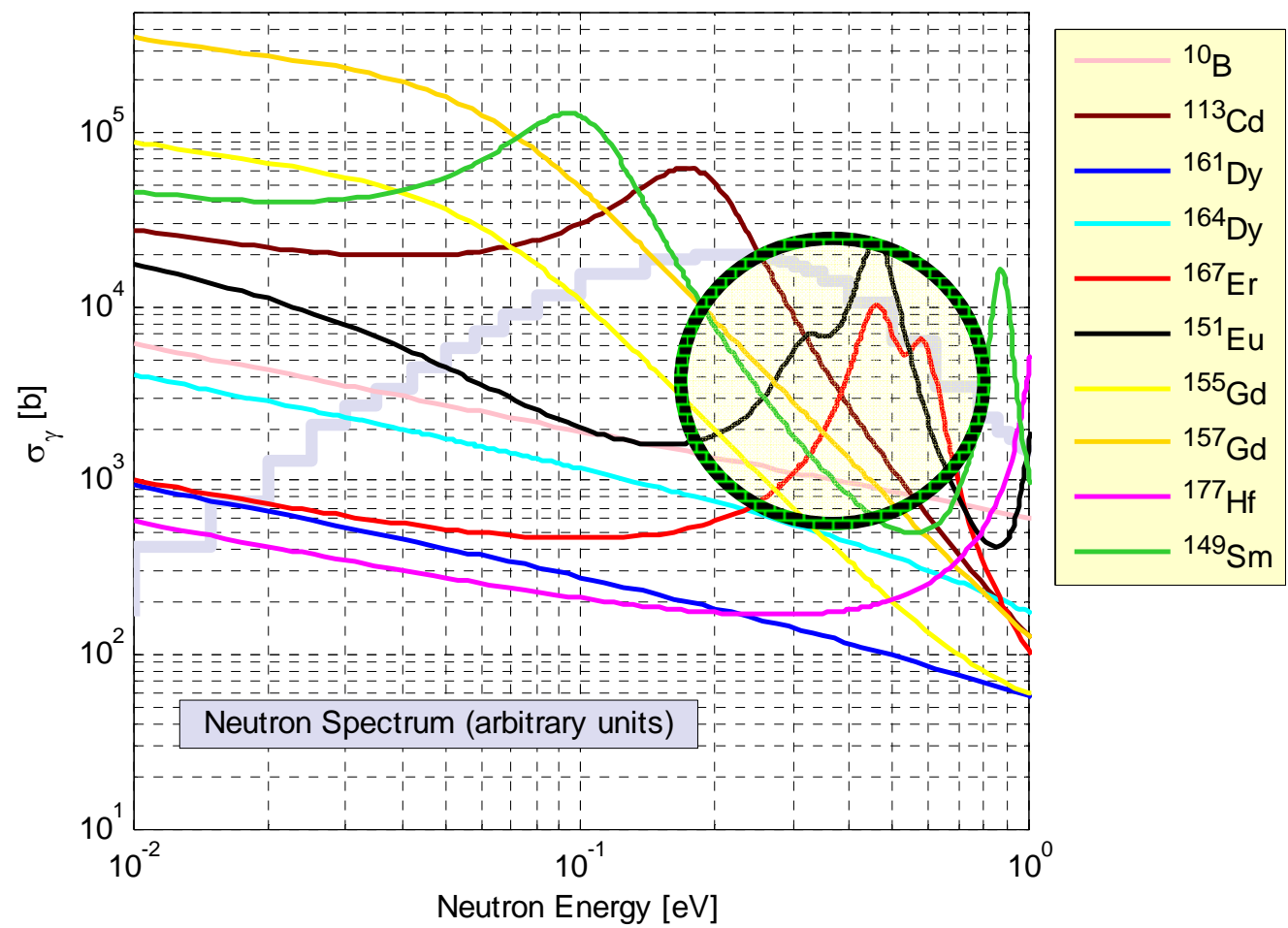

Figure 2. Microscopic absorption cross section of ${ }^{10} \mathrm{~B},{ }^{113} \mathrm{Cd},{ }^{167} \mathrm{Er},{ }^{151} \mathrm{Eu},{ }^{155} \mathrm{Gd},{ }^{157} \mathrm{Gd},{ }^{161} \mathrm{Dy}$, ${ }^{164} \mathrm{Dy},{ }^{177} \mathrm{Hf}$, and ${ }^{149} \mathrm{Sm}$ in the thermal energy range, $0.01-1 \mathrm{eV}$ and neutron spectrum of a prismatic HTR (lavender color and arbitrary units). The black circle highlights the increase of the europium and erbium absorption cross section in the region where the neutron spectrum (averaged in the core) decreases. The data of the neutron spectrum curve have been retrieved from Ref. 11

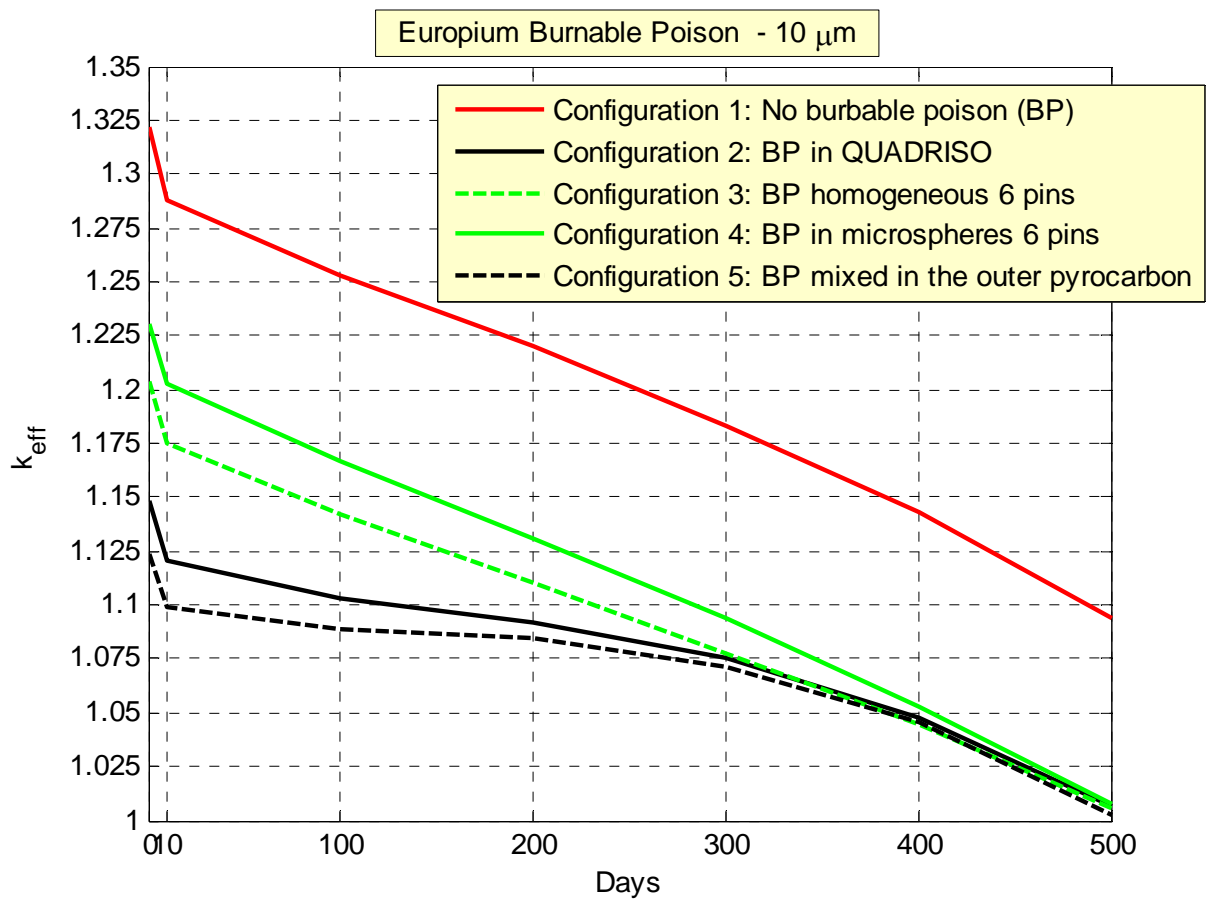

Figure 3. Multiplication factor as function of time for the europium burnable poison. The standard deviation is less than $60 \mathrm{pcm}$. The QUADRISO absorber layer thickness is equal to $10 \mu \mathrm{m}$ 


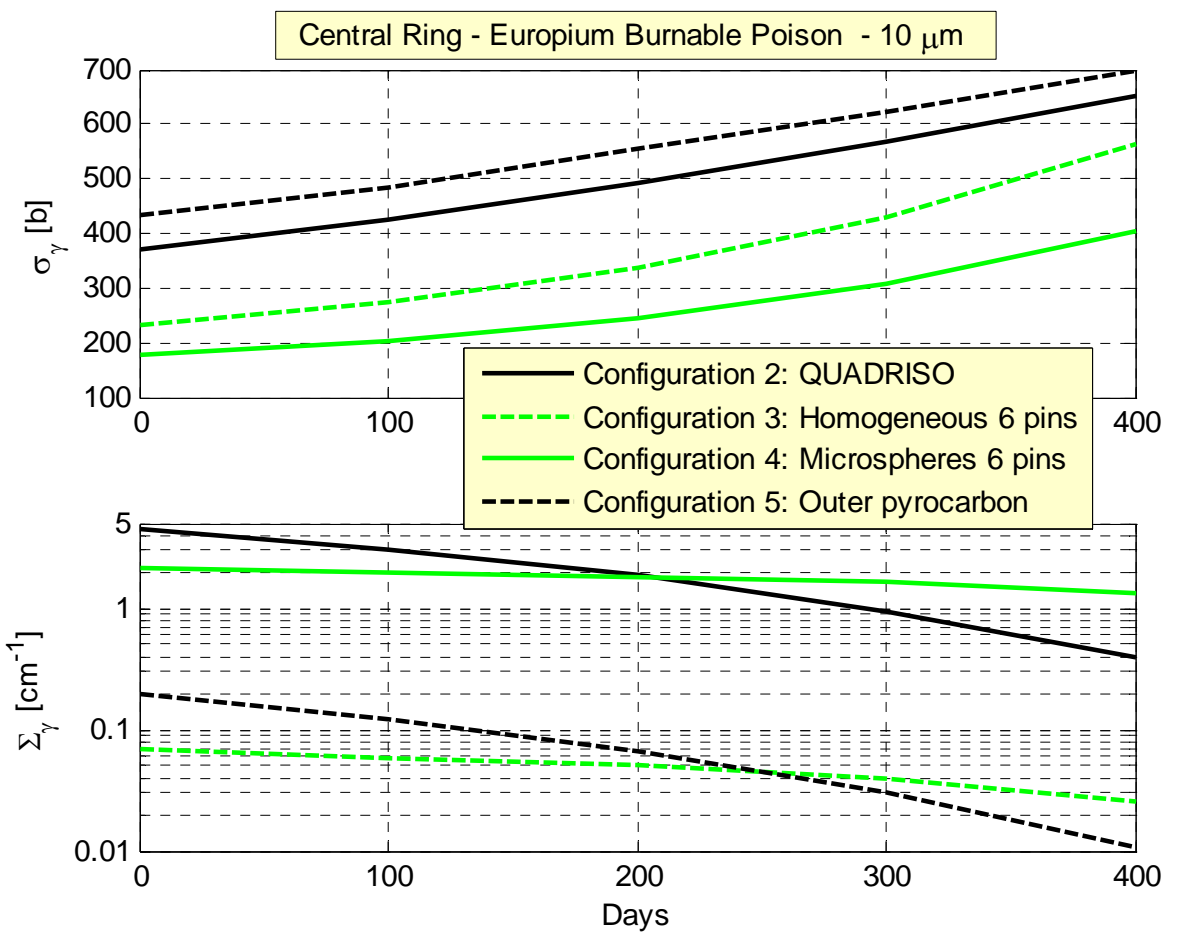

Figure 4. Microscopic and macroscopic cross sections of ${ }^{151} \mathrm{Eu}$ as function of time for the europium burnable poison. The QUADRISO absorber layer thickness is equal to $10 \mu \mathrm{m}$. For configurations 3 and 5, the poison is distributed over a 40 and 26 times, respectively, higher volume relative to the QUADRISO configuration

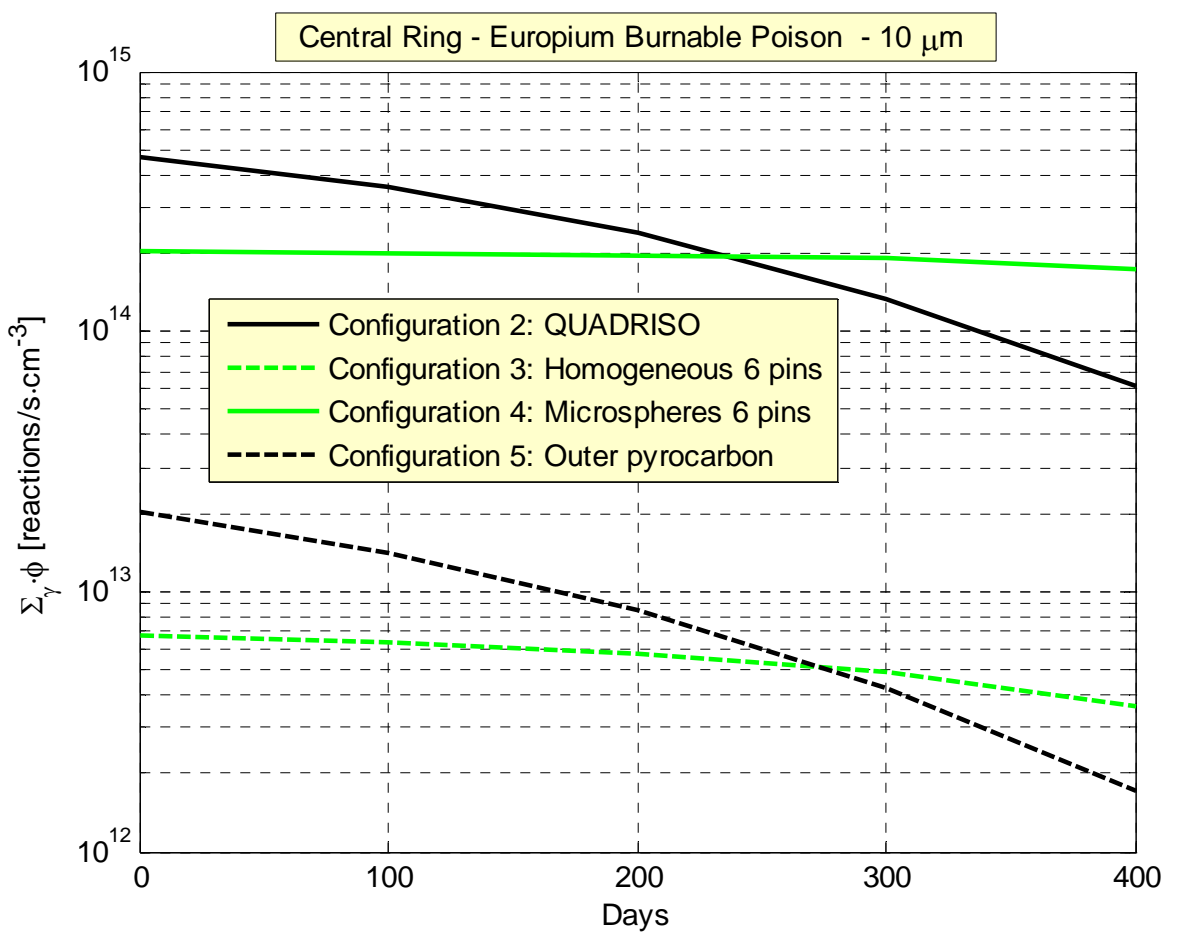

Figure 5. Capture reaction rate of ${ }^{151} \mathrm{Eu}$ as function of time for the europium burnable poison. The QUADRISO absorber layer thickness is equal to $10 \mu \mathrm{m}$. For configurations 3 and 5 , the poison is distributed over a 40 and 26 times, respectively, higher volume relative to the QUADRISO configuration 


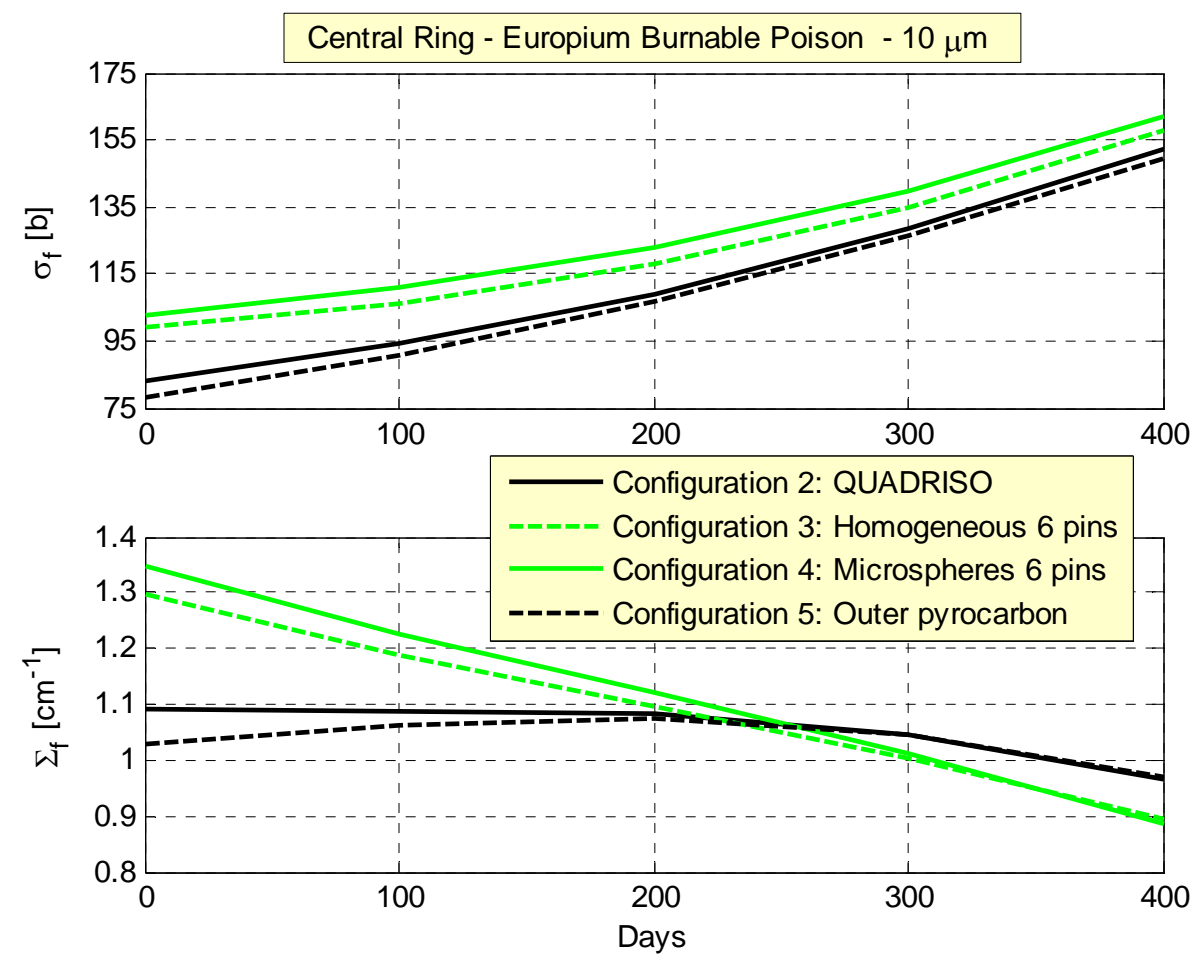

Figure 6. Microscopic and macroscopic fission cross sections of ${ }^{239} \mathrm{Pu}$ in the central ring as function of time for the europium burnable poison. The QUADRISO absorber layer thickness is equal to $10 \mu \mathrm{m}$

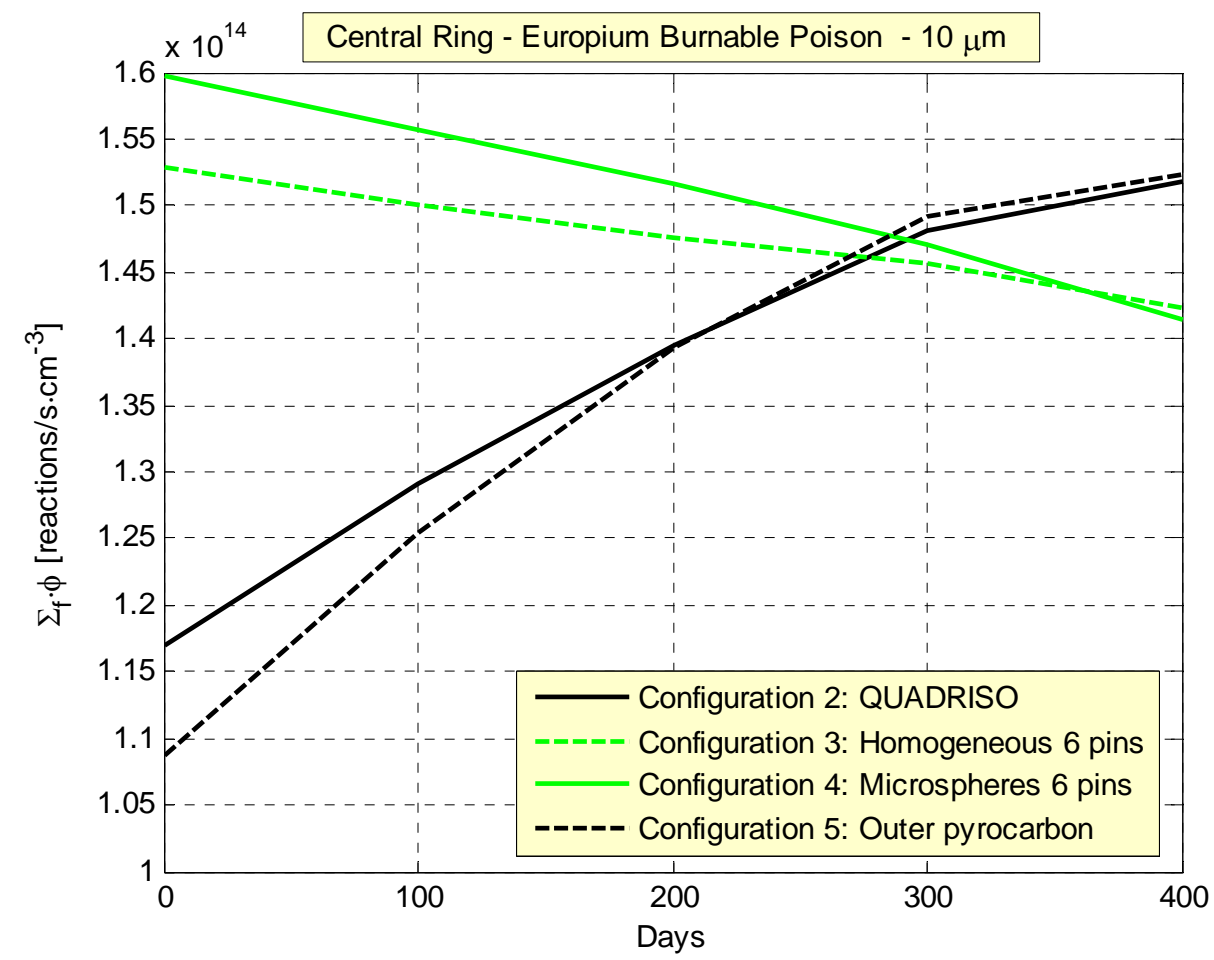

Figure 7. Fission reaction rate of ${ }^{239} \mathrm{Pu}$ in the central ring as function of time for the europium burnable poison. The QUADRISO absorber layer thickness is equal to $10 \mu \mathrm{m}$ 

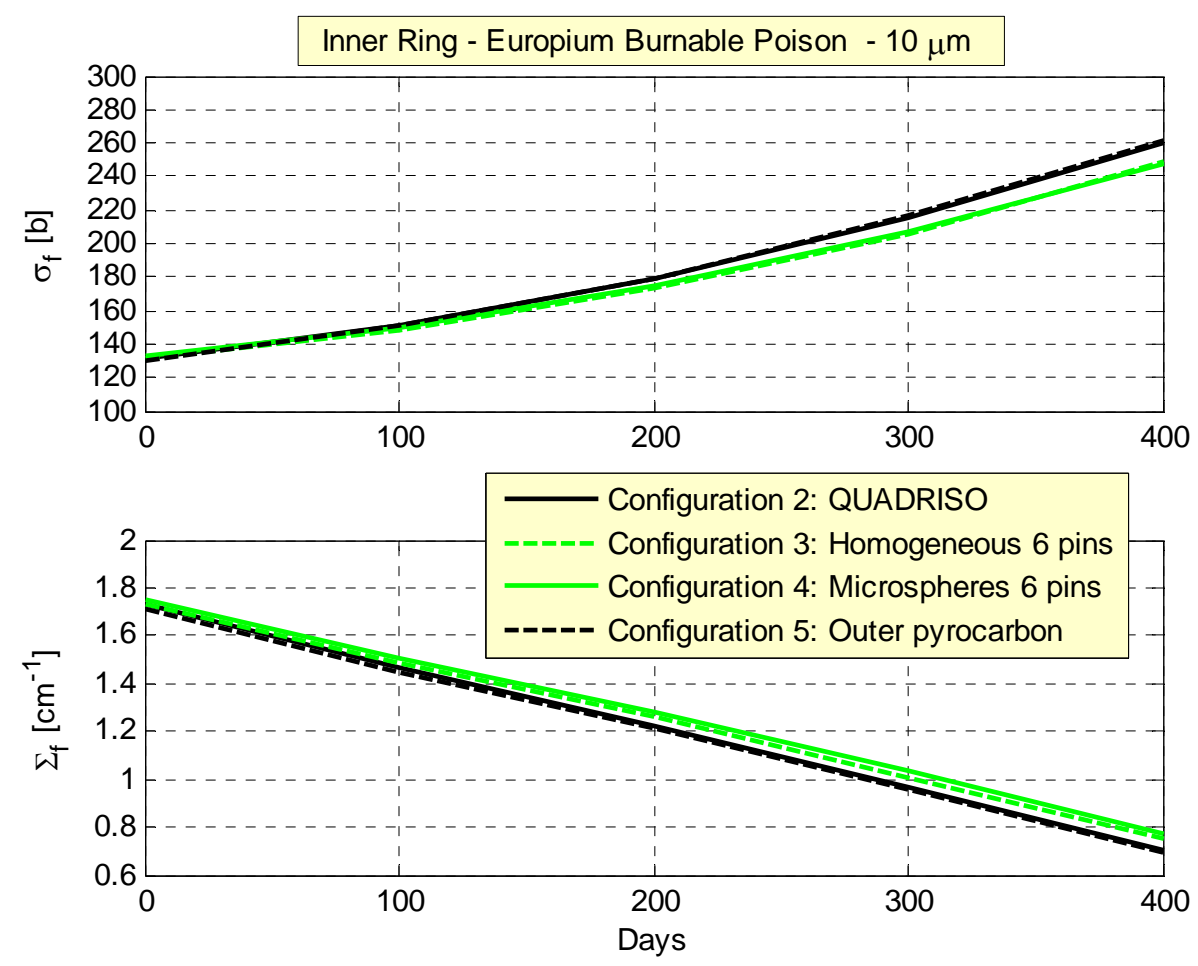

Figure 8. Microscopic and macroscopic cross sections of ${ }^{239} \mathrm{Pu}$ in the inner ring as function of time for the europium burnable poison

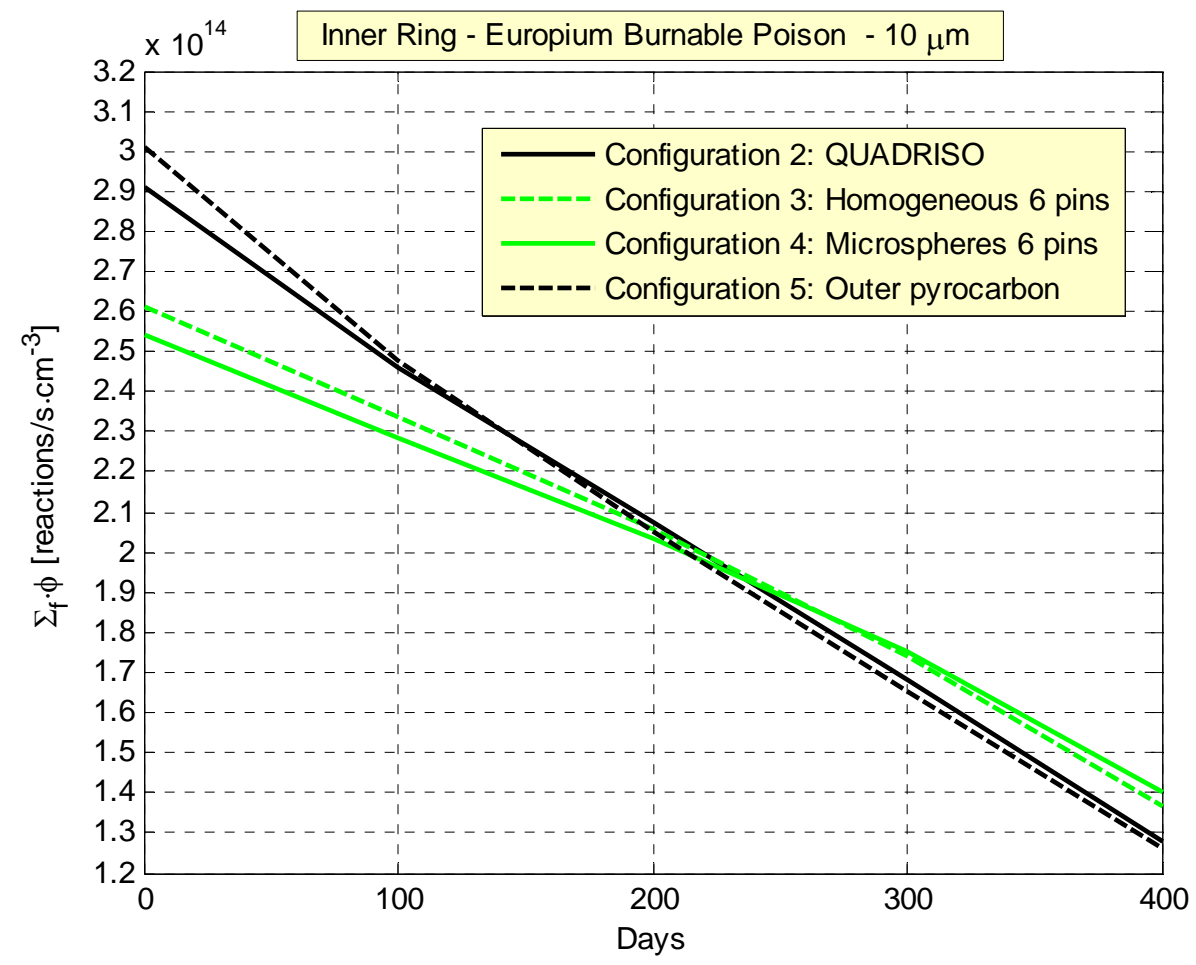

Figure 9. Fission reaction rate of ${ }^{239} \mathrm{Pu}$ in the inner ring as function of time for the europium burnable poison 


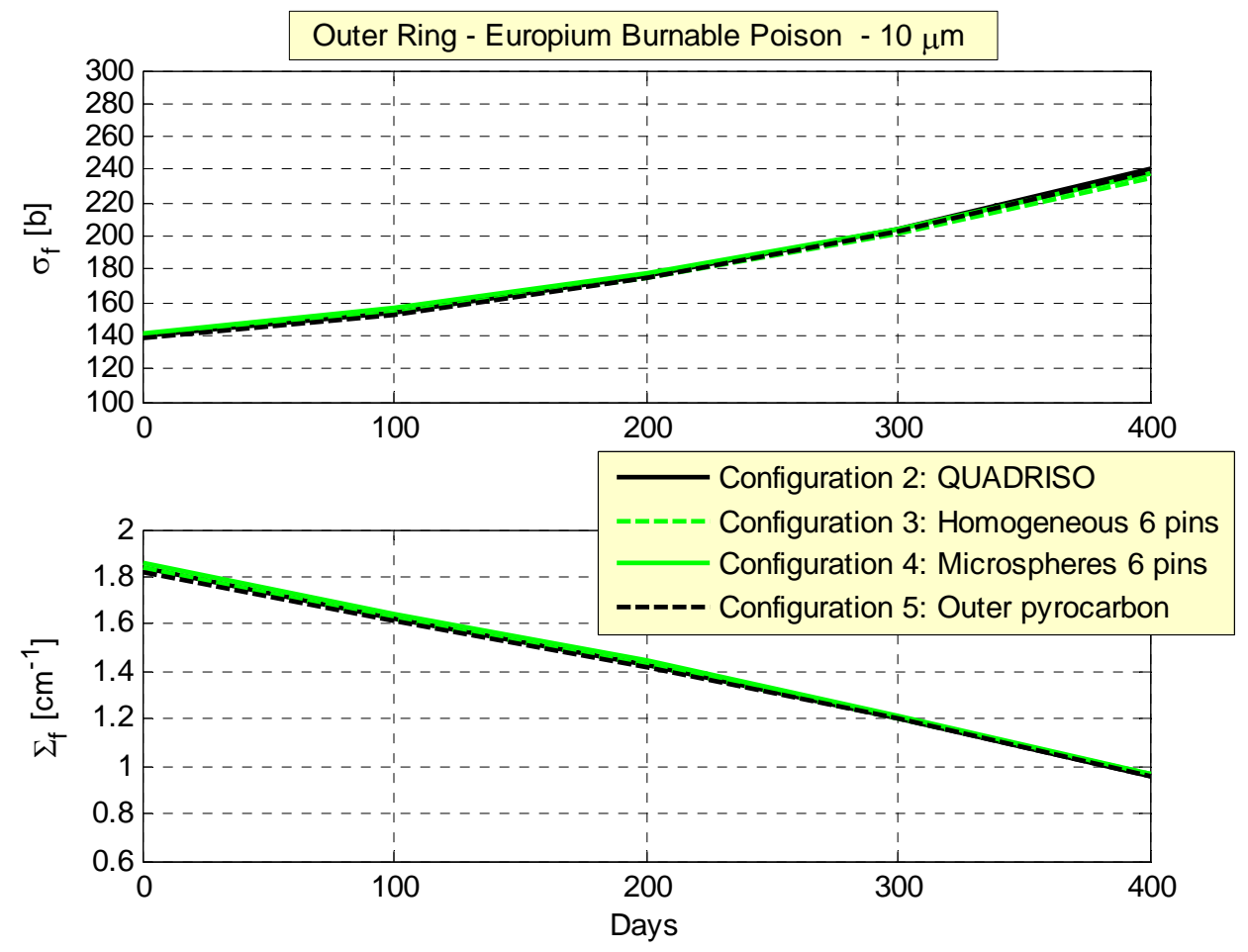

Figure 10. Microscopic and macroscopic cross sections of ${ }^{239} \mathrm{Pu}$ in the outer ring as function of time for the europium burnable poison

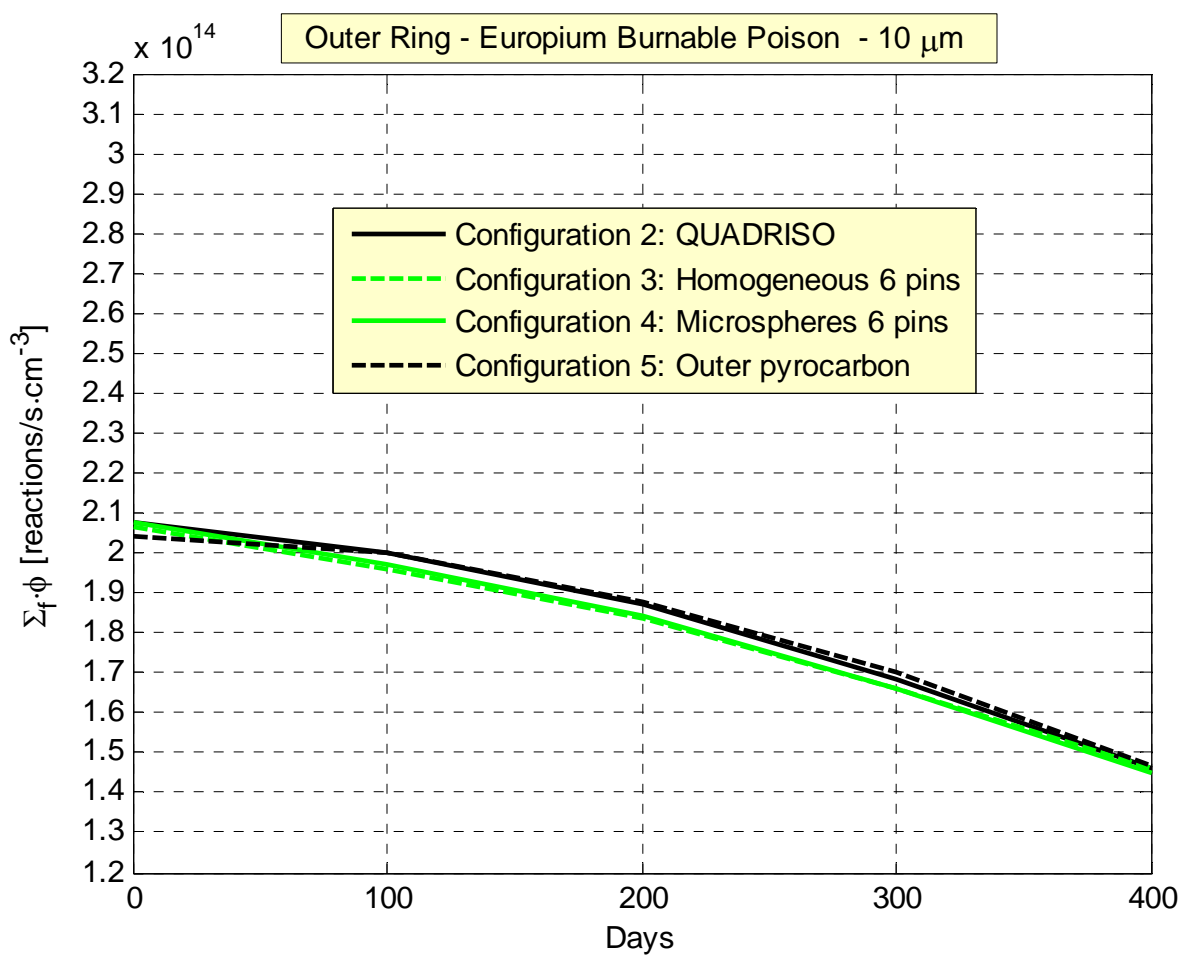

Figure 11. Fission reaction rate of ${ }^{239} \mathrm{Pu}$ in the outer ring as function of time for the europium burnable poison 


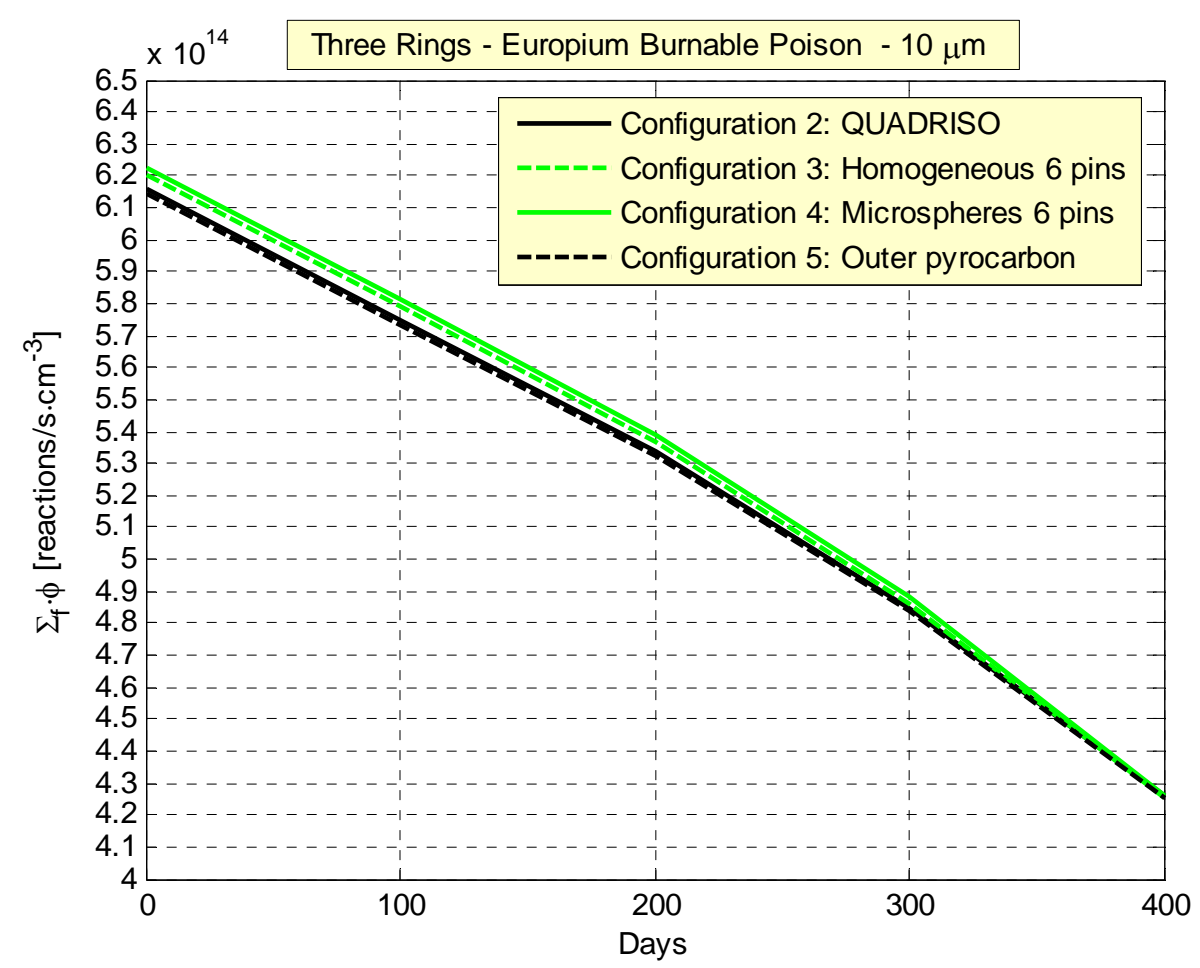

Figure 12. Fission reaction rate of ${ }^{239} \mathrm{Pu}$ in the three rings as function of time for the europium burnable poison
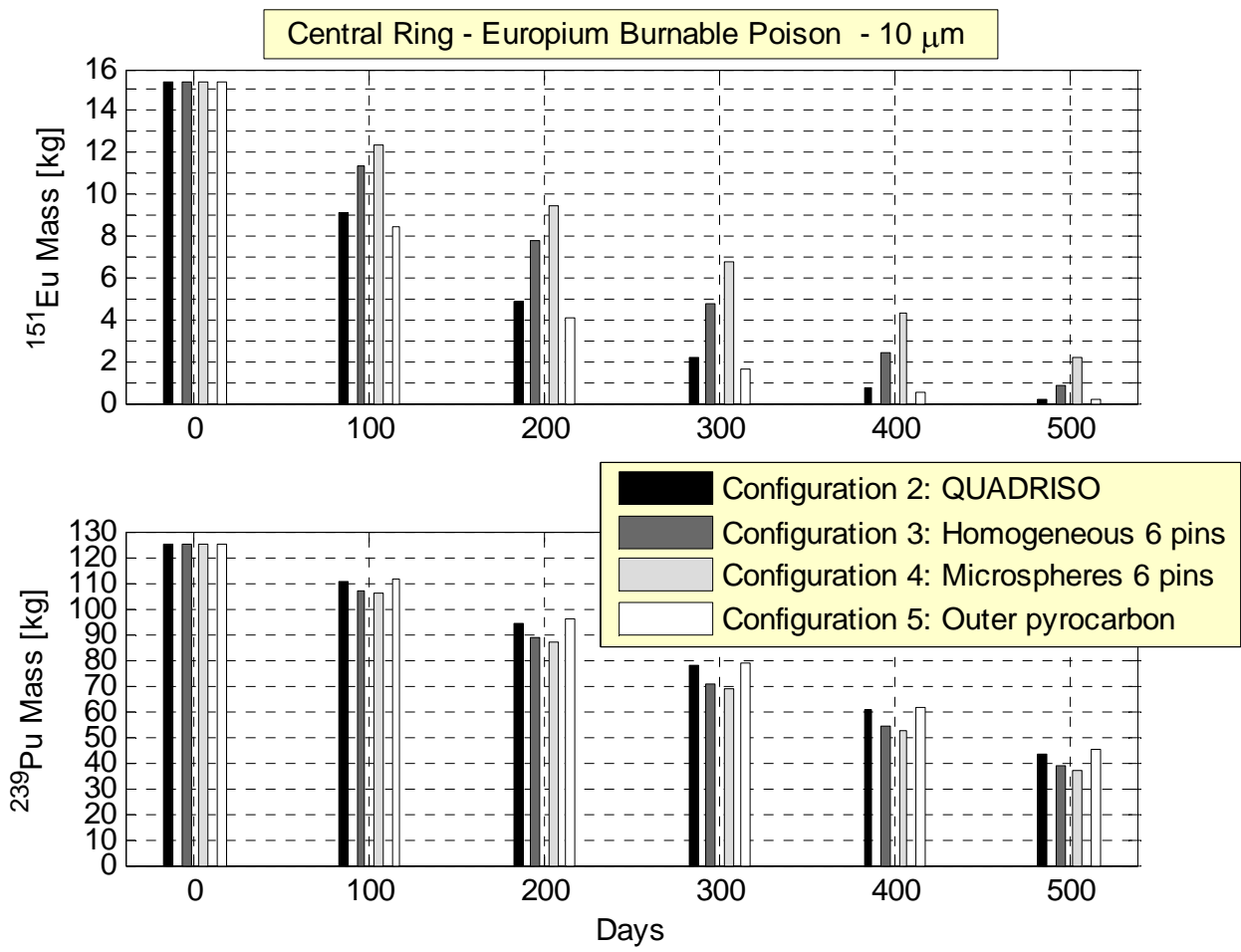

Figure 13. Mass of ${ }^{151} \mathrm{Eu}$ and ${ }^{239} \mathrm{Pu}$ as function of time for the europium burnable poison of the central ring of the core. The QUADRISO absorber layer thickness is $10 \mu \mathrm{m}$ 


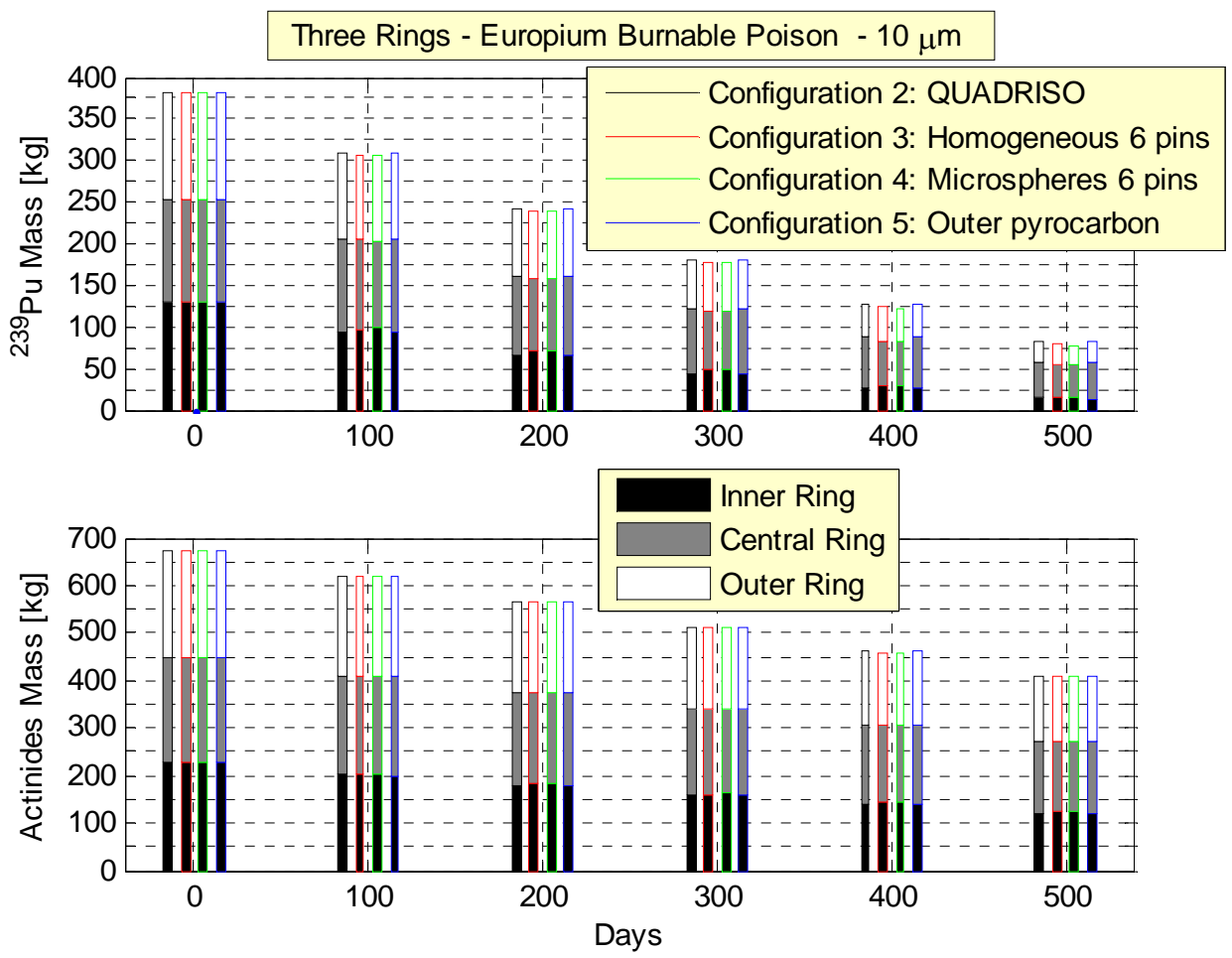

Figure 14. Mass of ${ }^{239} \mathrm{Pu}$ and actinides as function of time for the europium burnable poison. The QUADRISO absorber layer thickness is equal to $10 \mu \mathrm{m}$

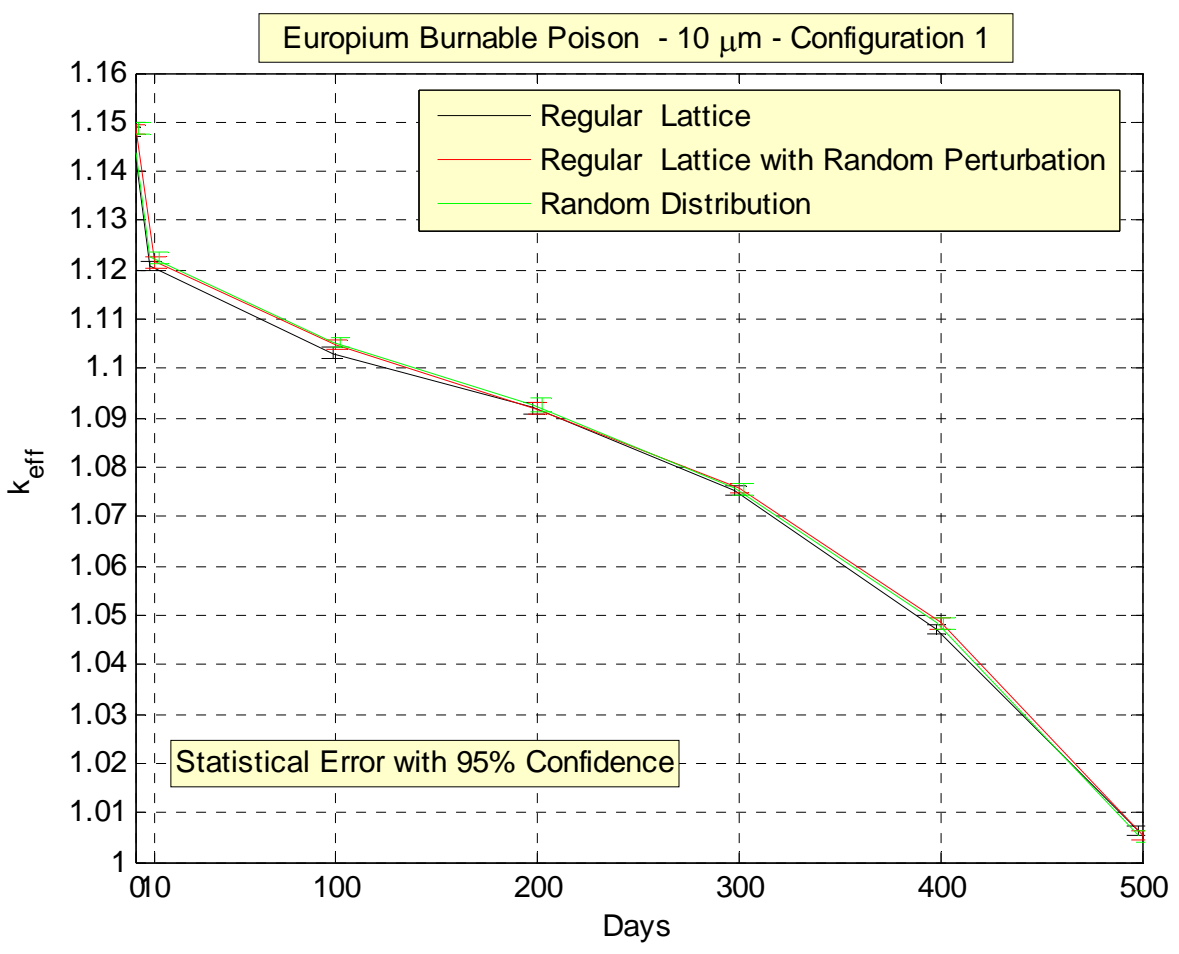

Figure 15. Multiplication factor for configuration 1 (QUADRISO) as function of time for particles distributed in regular lattice, regular lattice with random perturbation, and random distribution 


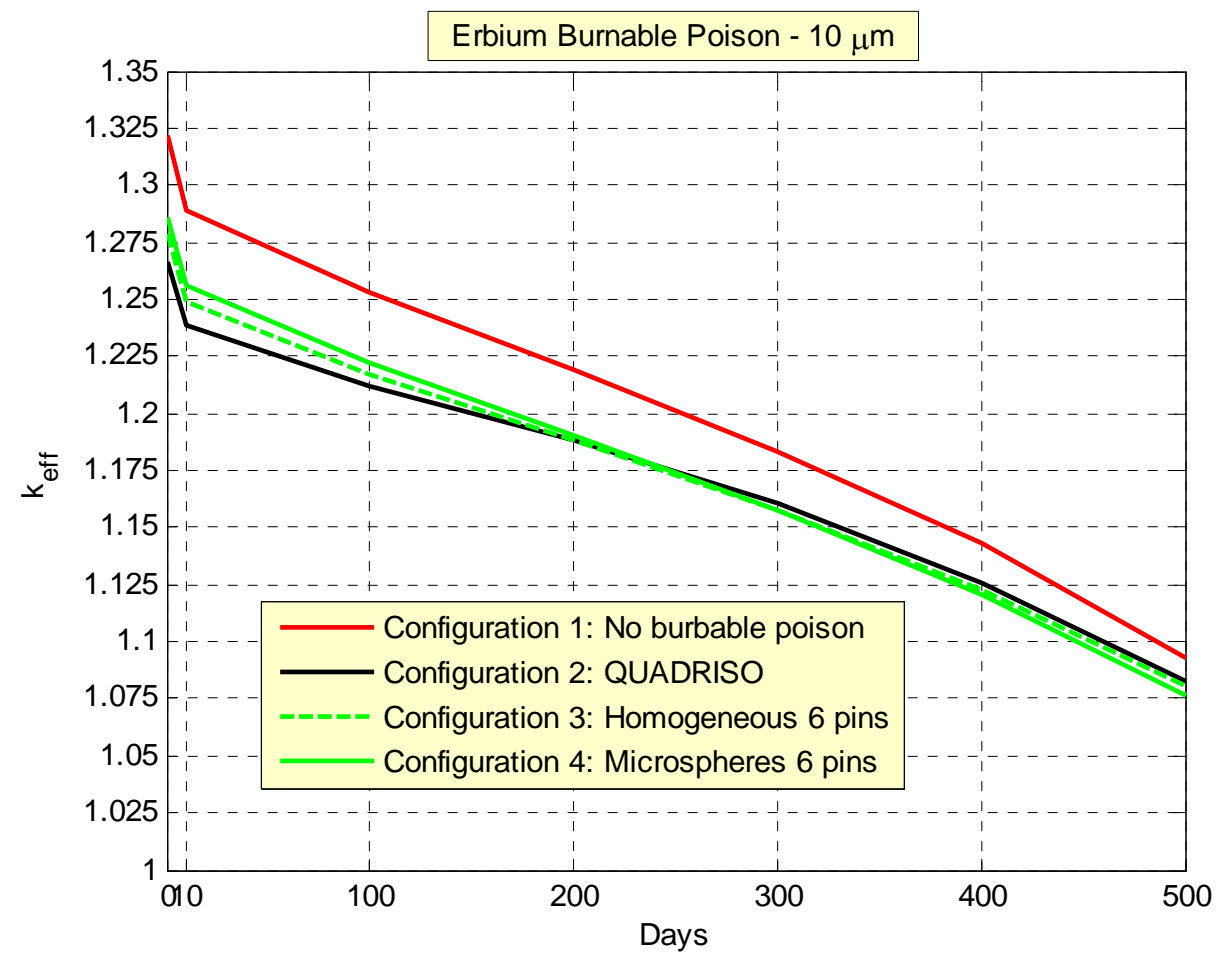

Figure 16. Multiplication factor as function of time for the erbium burnable poison. Standard deviation lower than $60 \mathrm{pcm}$. The QUADRISO absorber layer thickness is equal to $10 \mu \mathrm{m}$
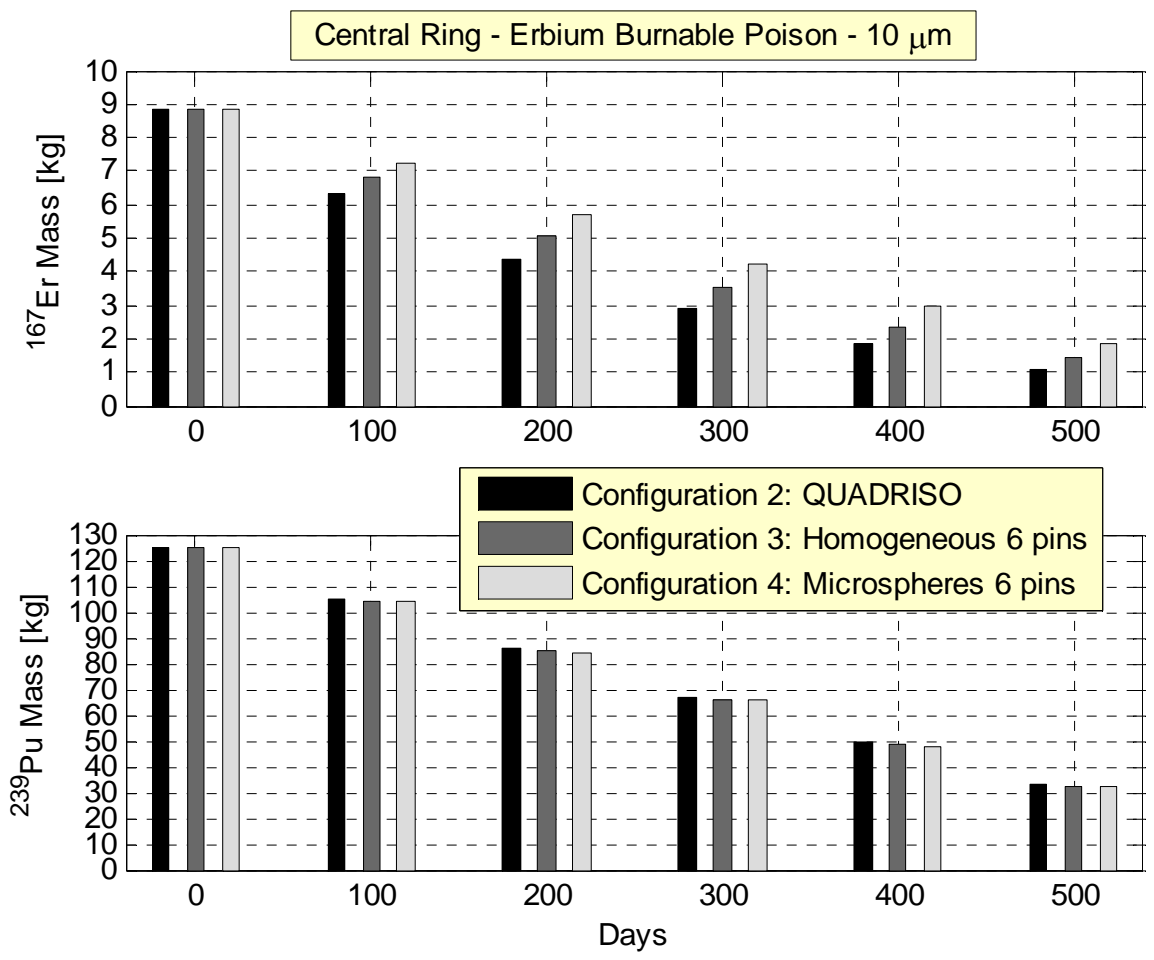

Figure 17. Mass of ${ }^{167} \mathrm{Er}$ and ${ }^{239} \mathrm{Pu}$ as function of time for the erbium burnable poison. The QUADRISO absorber layer thickness is equal to $10 \mu \mathrm{m}$ 


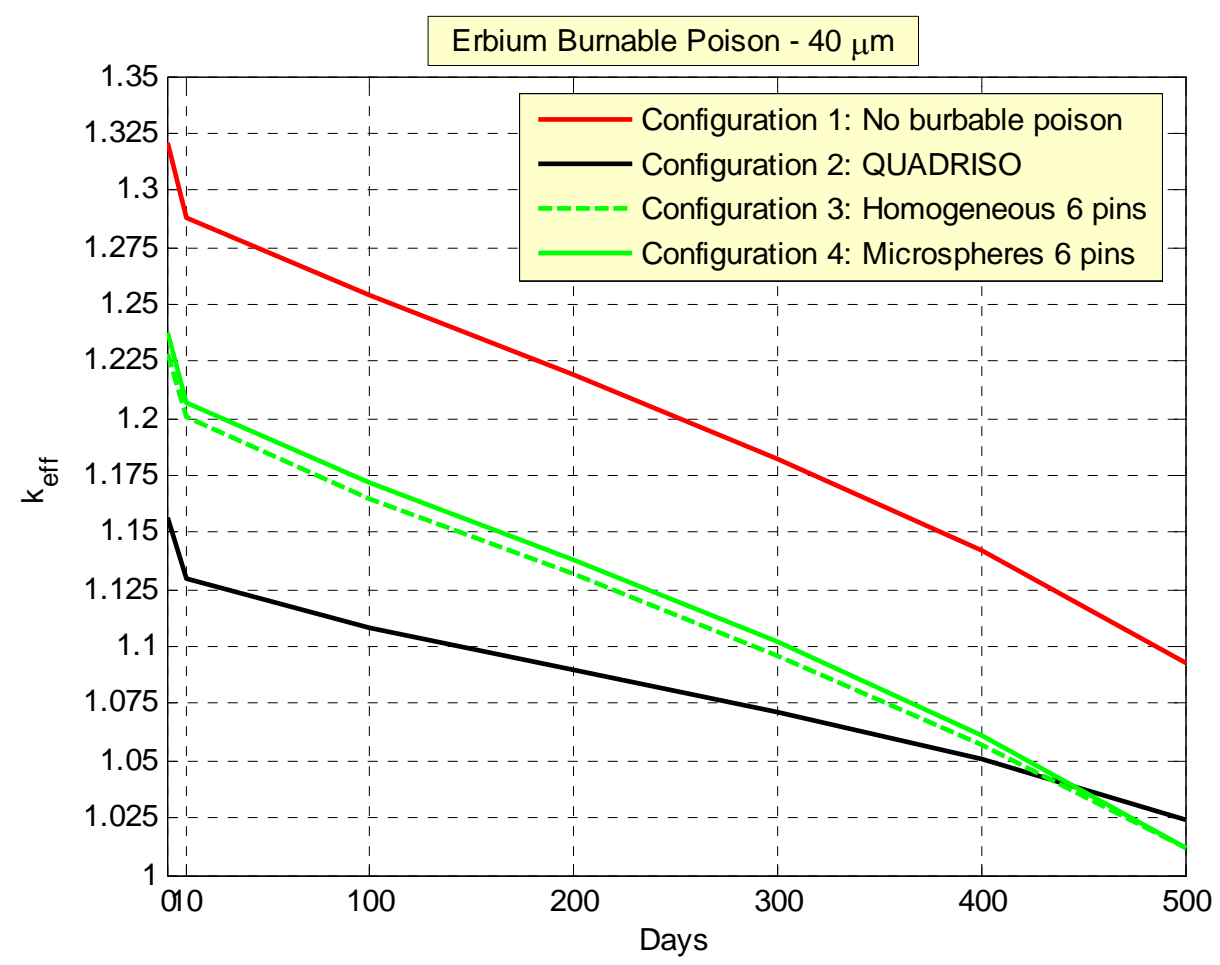

Figure 18. Multiplication factor as function of time for the erbium burnable poison. Standard deviation lower than $63 \mathrm{pcm}$. The QUADRISO absorber layer thickness is equal to $40 \mu \mathrm{m}$
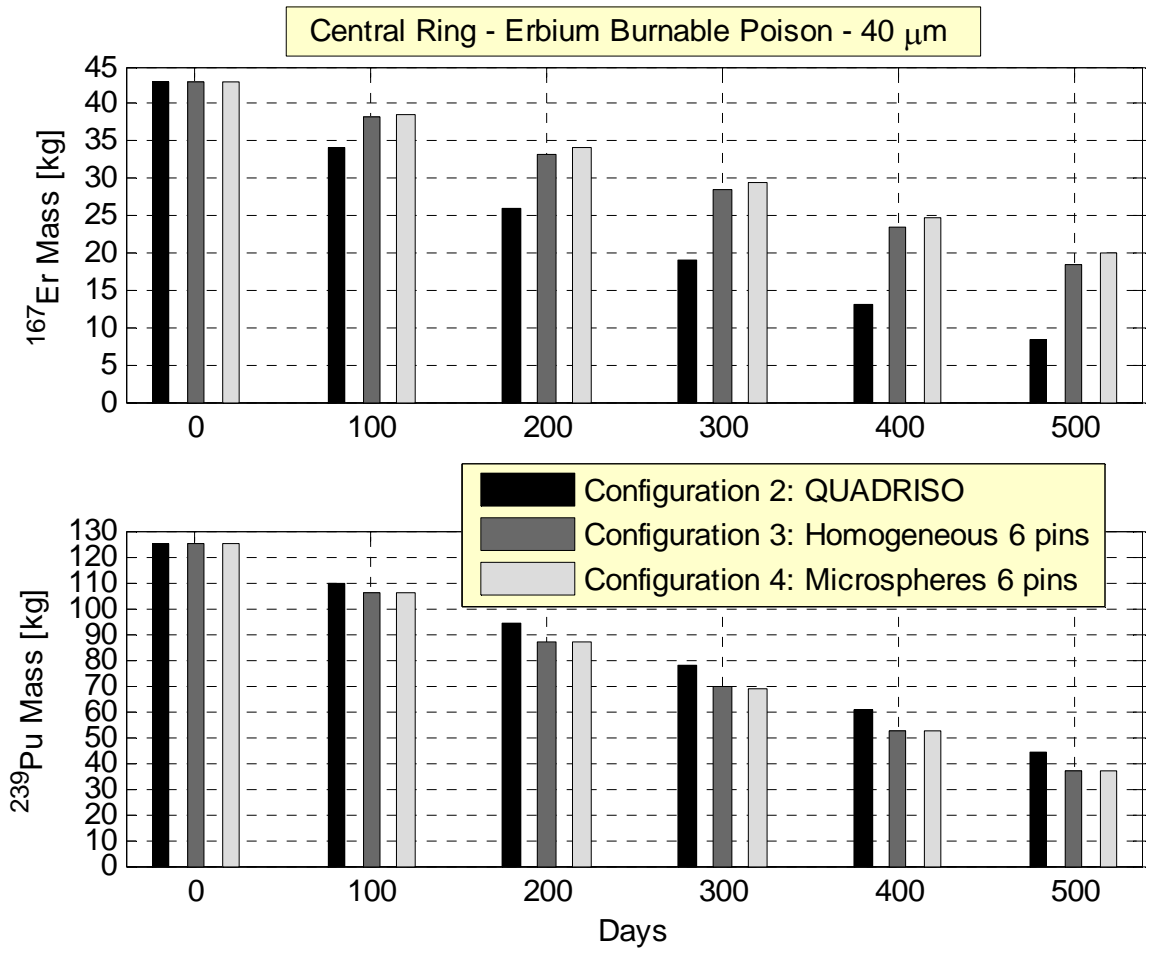

Figure 19. Mass of ${ }^{167} \mathrm{Er}$ and ${ }^{239} \mathrm{Pu}$ as function of time for the erbium burnable poison. The QUADRISO absorber layer thickness is equal to $40 \mu \mathrm{m}$ 


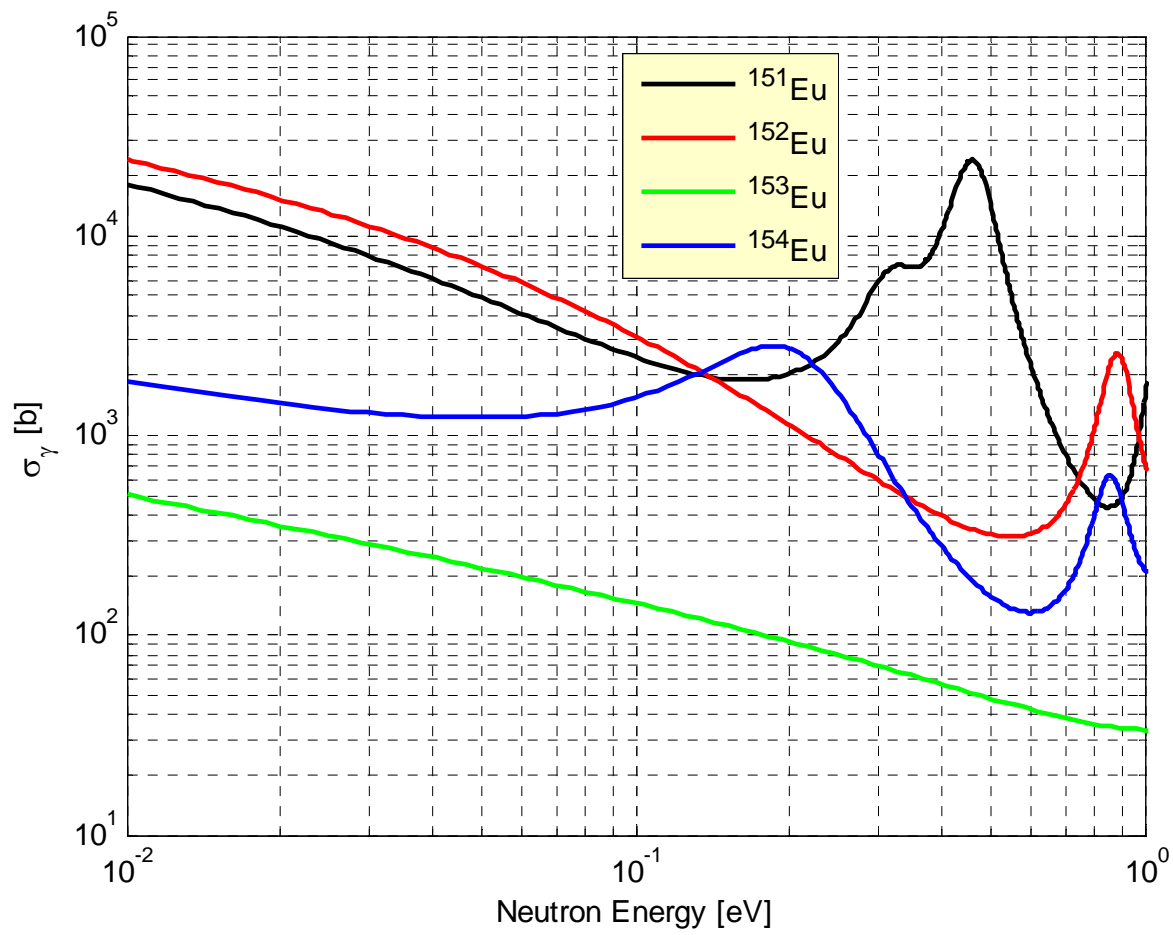

Figure 20. Microscopic absorption cross section of ${ }^{151} \mathrm{Eu},{ }^{152} \mathrm{Eu},{ }^{153} \mathrm{Eu}$, and ${ }^{154} \mathrm{Eu}$, in the thermal energy range, $0.01-1 \mathrm{eV}$

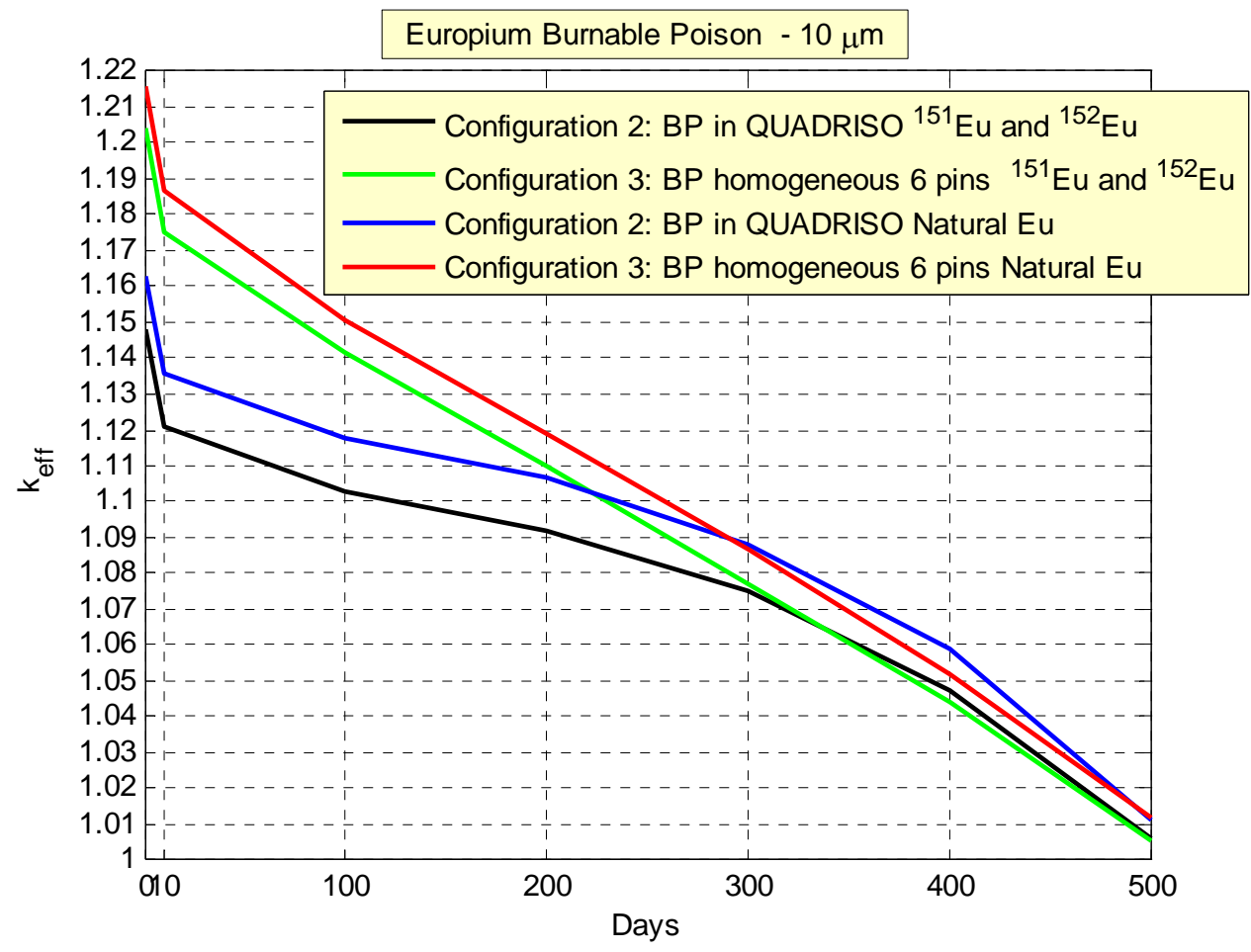

Figure 21. Multiplication factor as function of time for different compositions of the europium burnable poison. The standard deviation is less than $63 \mathrm{pcm}$. The QUADRISO absorber layer thickness is equal to $10 \mu \mathrm{m}$ 


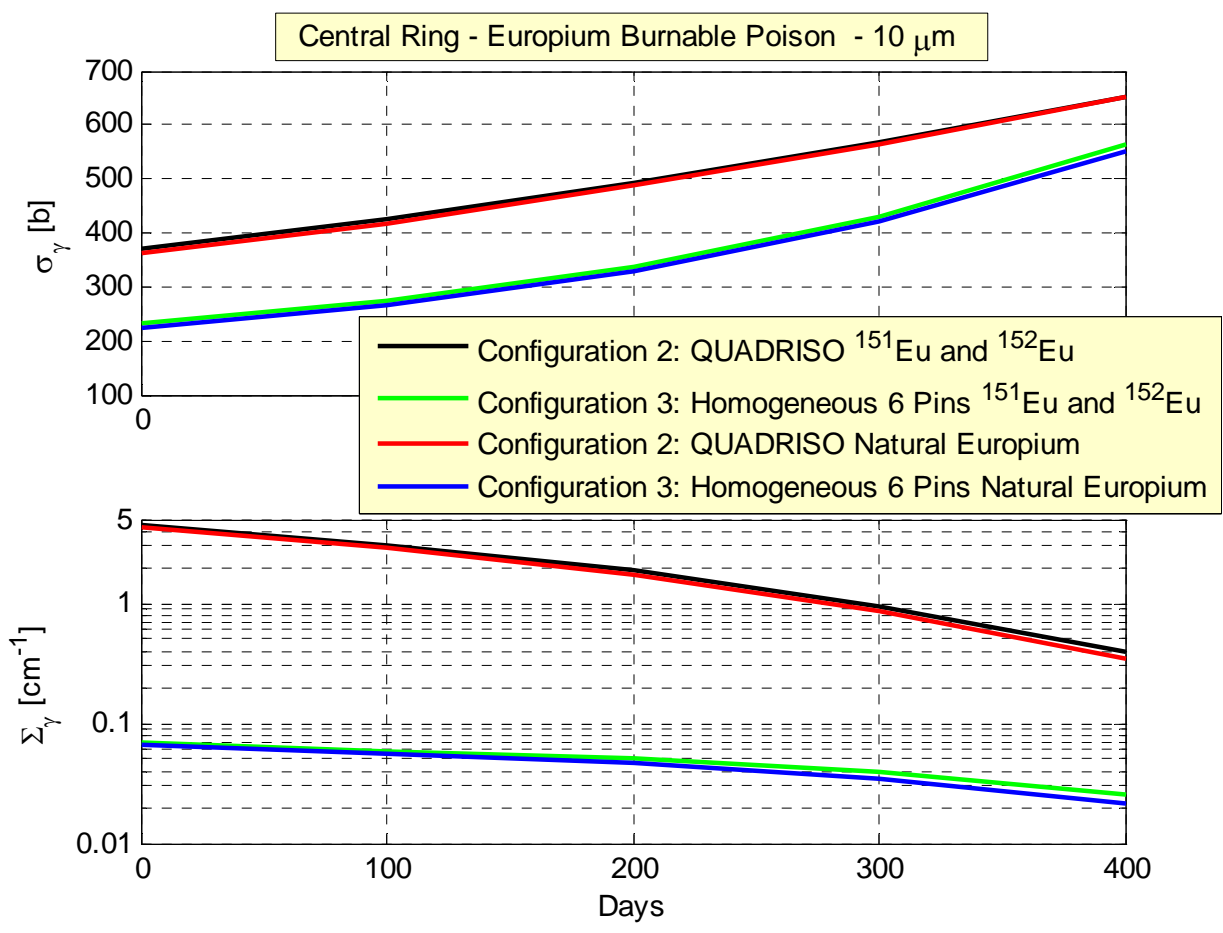

Figure 22. Microscopic and macroscopic cross sections of ${ }^{151} \mathrm{Eu}$ as function of time for different compositions of the europium burnable poison. The QUADRISO absorber layer thickness is equal to $10 \mu \mathrm{m}$. For configurations 3 and 5 , the poison is distributed over a 40 and 26 times, respectively, higher volume relative to the QUADRISO configuration

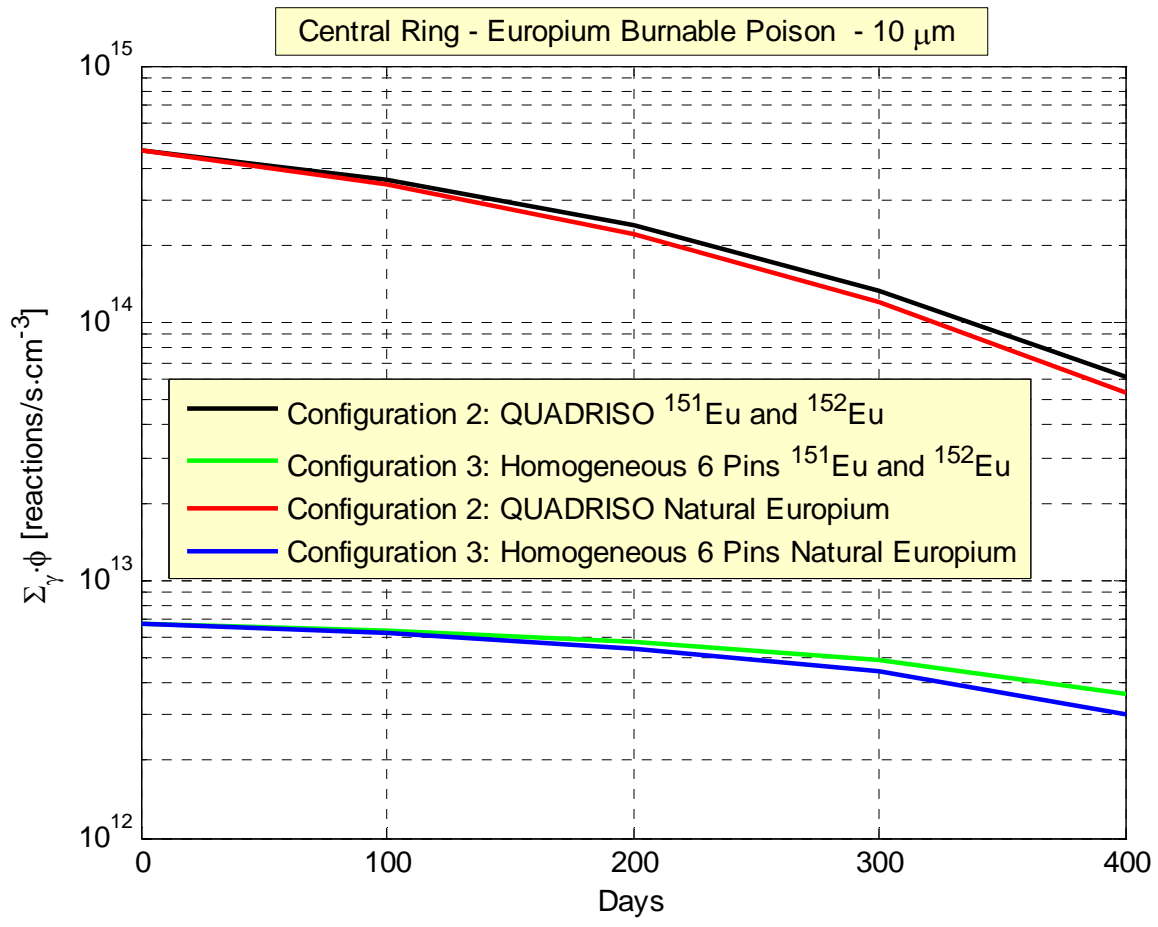

Figure 23. Capture reaction rate of ${ }^{151} \mathrm{Eu}$ as function of time for different compositions of the the europium burnable poison. The QUADRISO absorber layer thickness is equal to $10 \mu \mathrm{m}$. For configurations 3 and 5, the poison is distributed over a 40 and 26 times, respectively, higher volume relative to the QUADRISO configuration 


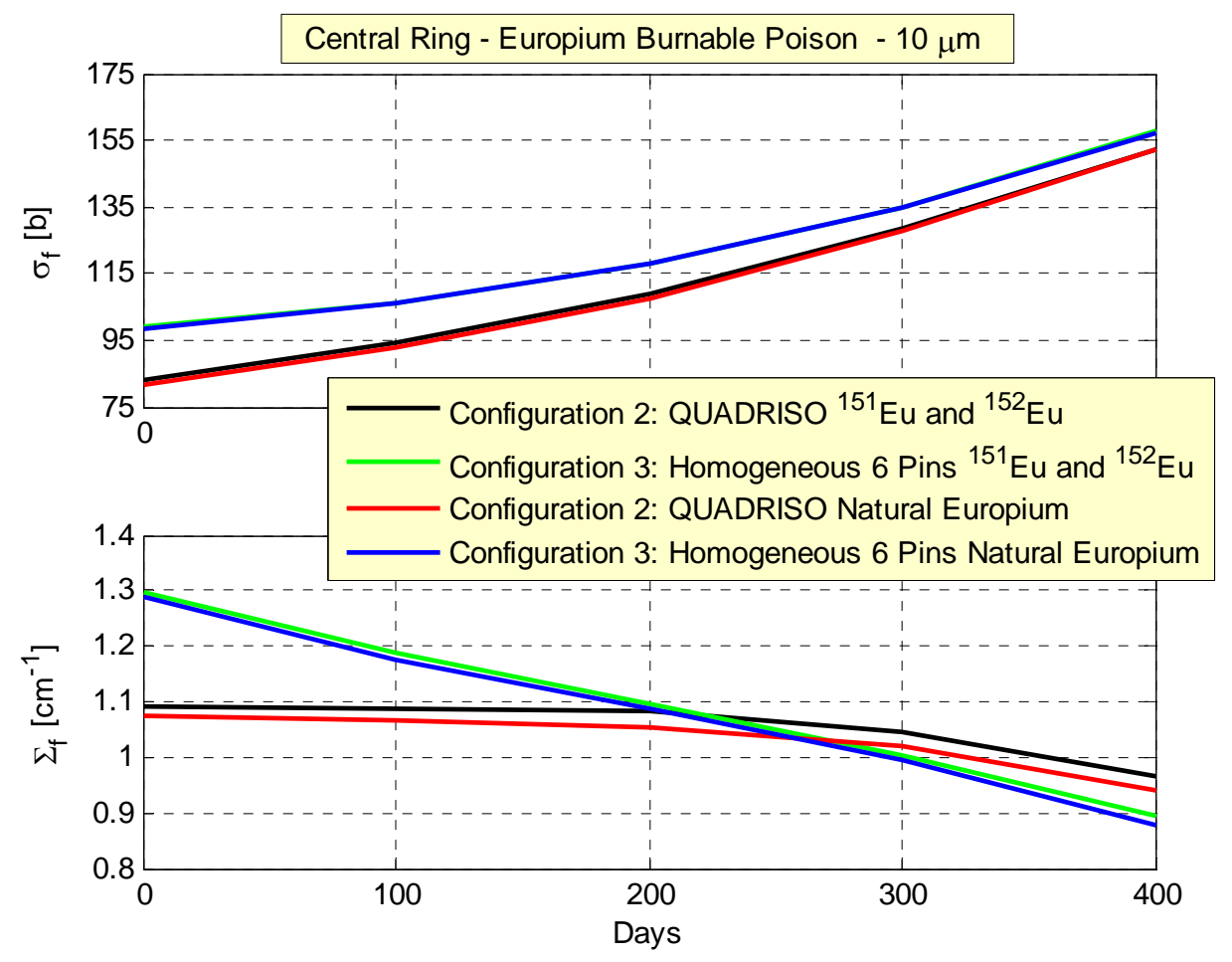

Figure 24. Microscopic and macroscopic fission cross sections of ${ }^{239} \mathrm{Pu}$ in the central ring as function of time for different compositions of the the europium burnable poison. The QUADRISO absorber layer thickness is equal to $10 \mu \mathrm{m}$

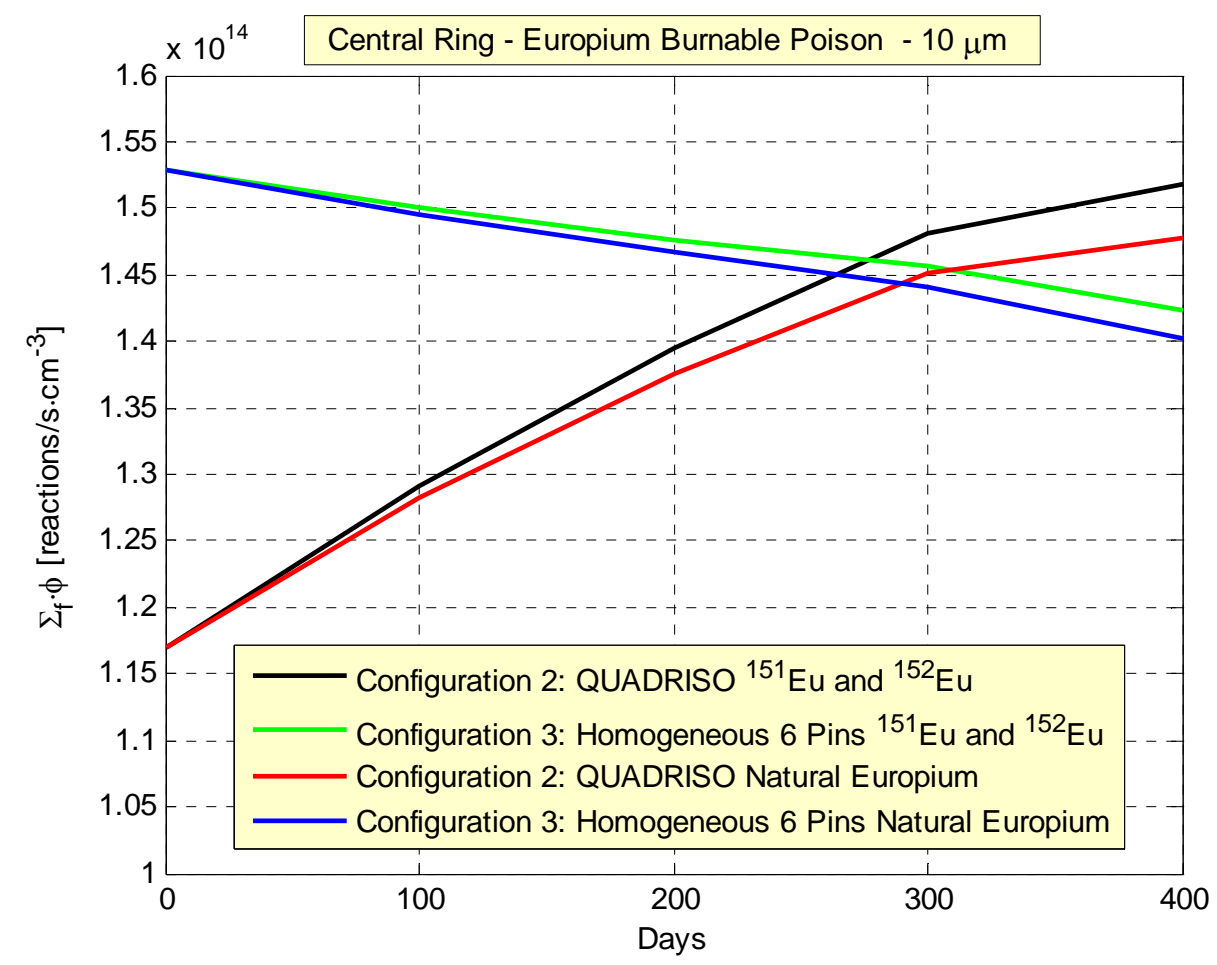

Figure 25. Fission reaction rate of ${ }^{239} \mathrm{Pu}$ in the central ring as function of time for different compositions of the europium burnable poison. The QUADRISO absorber layer thickness is equal to $10 \mu \mathrm{m}$ 

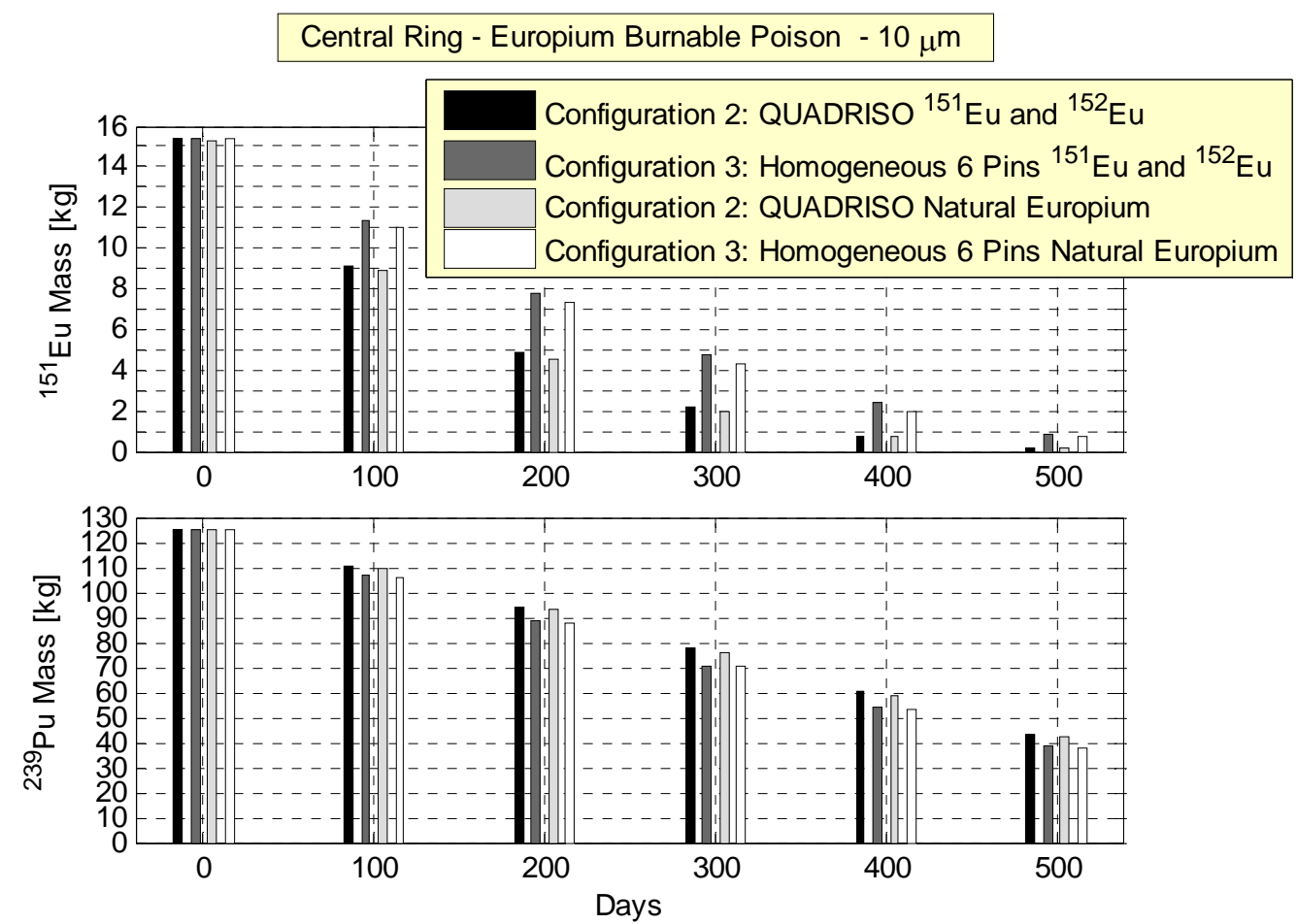

Figure 26. Mass of ${ }^{151} \mathrm{Eu}$ and ${ }^{239} \mathrm{Pu}$ as function of time for the europium burnable poison of the central ring of the core. The QUADRISO absorber layer thickness is $10 \mu \mathrm{m}$

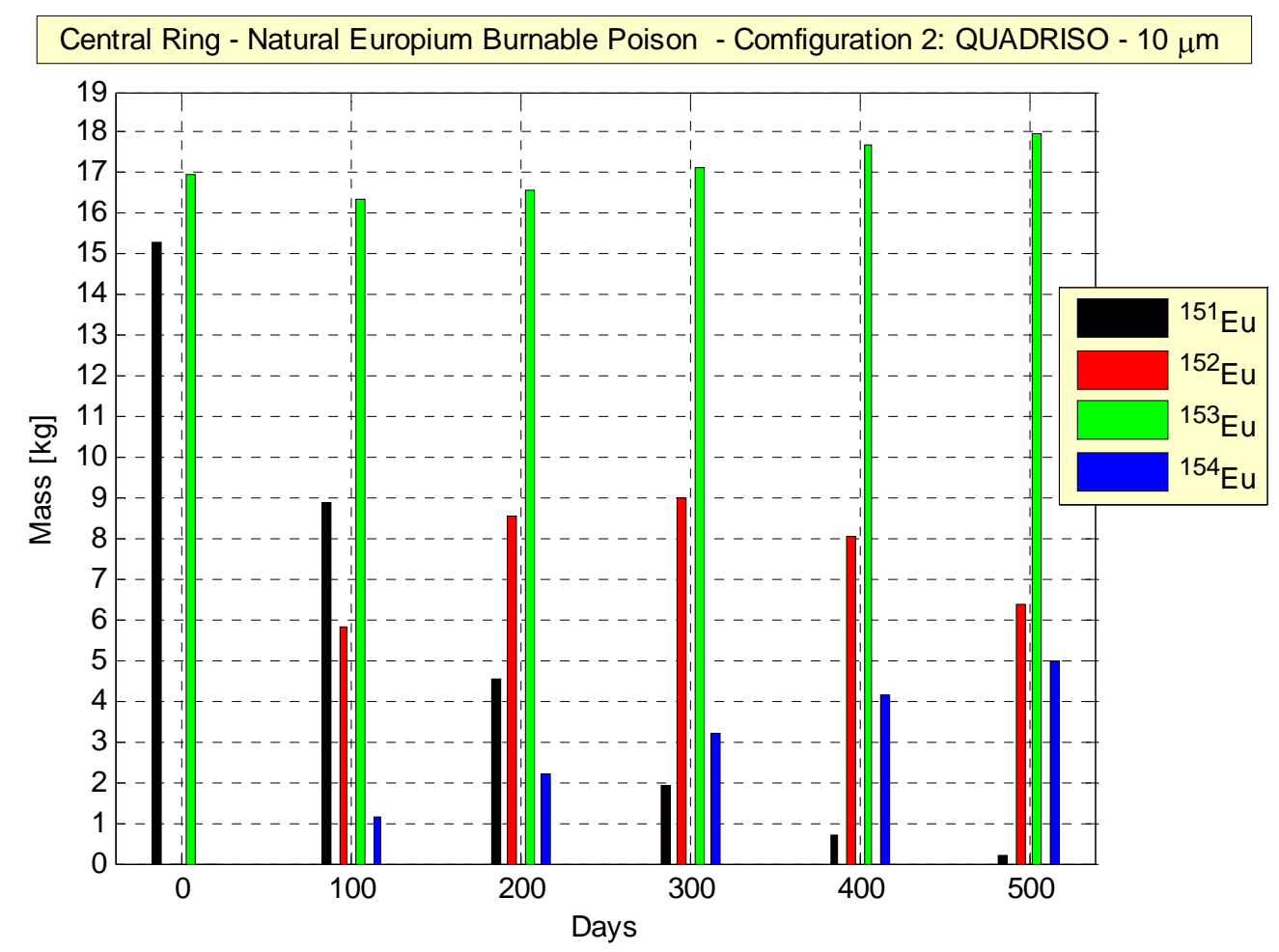

Figure 27. Mass of europium isotopes function of time for the natural europium burnable poison disposed in QUADRISO particles. The QUADRISO absorber layer thickness is $10 \mu \mathrm{m}$ 


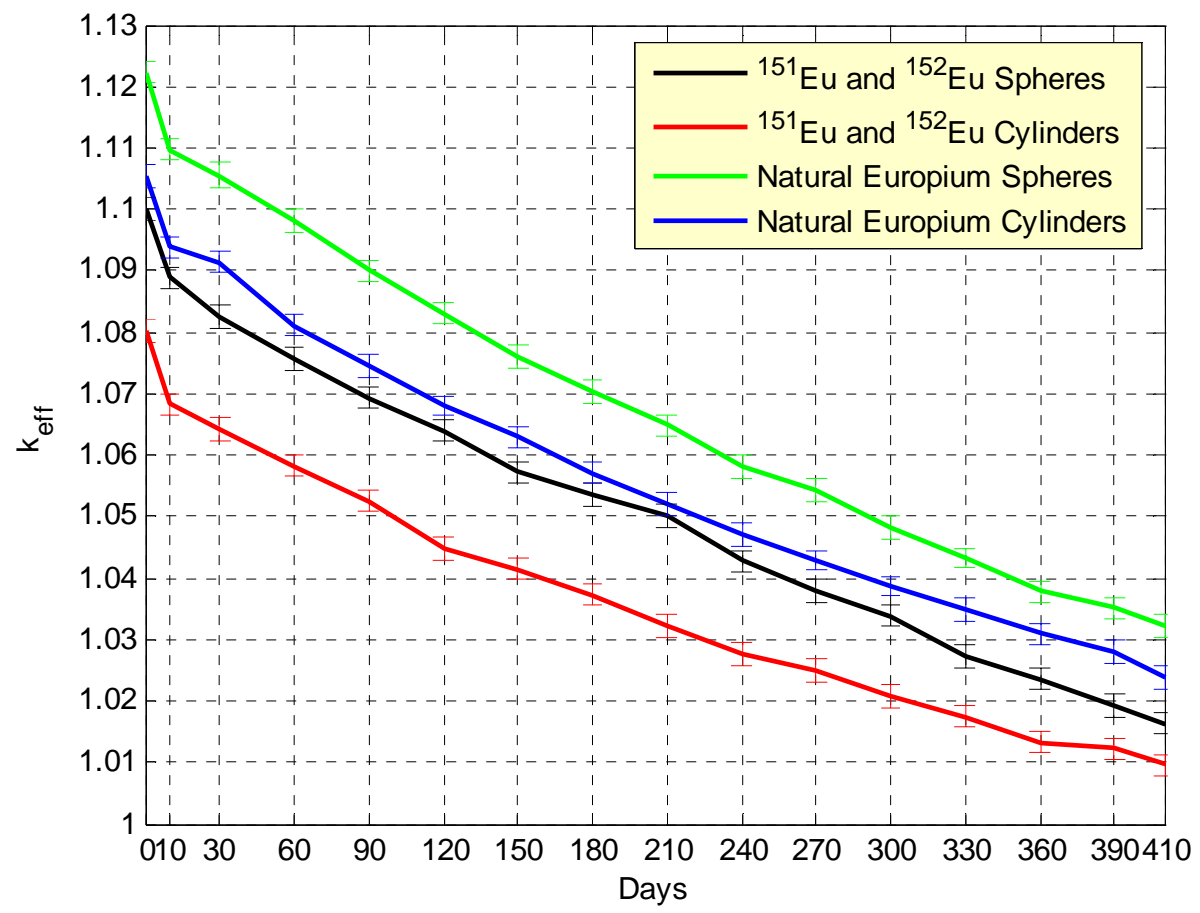

Figure 28. Keff evolution for different compositions of the europium burnable poison. The horizontal ticks indicate the statistical error with $95 \%$ confidence 


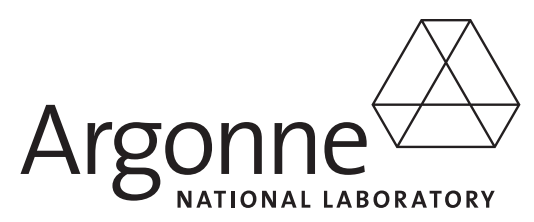

Nuclear Engineering Division

Argonne National Laboratory

9700 South Cass Avenue

Argonne, IL 60439

www.anl.gov 